\title{
Dinoflagelados (Peridiniales, Prorocentrales) do microplâncton na plataforma continental e talude do extremo sul do Brasil (inverno 2005, verão 2007)
}

\author{
Carolina Antuarte Islabão ${ }^{1,2}$ \& Clarisse Odebrecht ${ }^{1}$ \\ ${ }^{1}$ Programa de Pós-graduação em Oceanografia Biológica, Instituto de Oceanografia, \\ Universidade Federal do Rio Grande - FURG, Av. Itália, Km 8, CEP 96201-900, Rio Grande, RS, Brasil \\ ${ }^{2}$ Autor para correspondência: Carolina Antuarte Islabão,e-mail: gcarolislabao@gmail.com
}

ISLABÃO, C.A. \& ODEBRECHT, C. Microplankton dinoflagellates (Peridiniales, Prorocentrales) at the continental shelf and slope in Southern Brasil (winter 2005, summer 2007). Biota Neotrop. 11(3): http:// www.biotaneotropica.org.br/v11n3/en/abstract?article+bn02511032011

\begin{abstract}
This study aimed at identifying morpho-species of microplankton dinoflagellates (> $20 \mu \mathrm{m})$ of the order Peridiniales and Prorocentrales off Santa Marta Grande Cape, CSMG (SC, 28 40' S) and Albardão-Chui, AC (RS, 34 40' S) during oceanographic cruises conducted in winter 2005 and summer 2007. Plankton samples were obtained by vertical net (mesh size $20 \mu \mathrm{m}$ ) hauls preserved with formaldehyde $4 \%$ and analyzed using the inverted microscope equipped with a digital camera. The identification of Peridiniales species was based on the number and morphology of thecal plates enhanced with Calco Fluor White MR2 whenever necessary and the identification of Prorocentrales was based on cell size, shape, presence of apical processes, pore pattern and marks at the intercalary band. We identified 25 species, including Protoperidinium (11), Prorocentrum (6), Corythodinium (3), Podolampas (2), Oxytoxum (2) and Heterocapsa (1). Prorocentrum species were widely distributed on the continental shelf of southern Brazil, while Peridiniales species were mainly found off Albardão-Chui during winter, especially under the influence of the plume of La Plata River. Oxytoxum milneri was the first time recorded in southern Brazil, while Protoperidinium cassum var. cassum, P. curtipes and Heterocapsa triquetra, were first registered in Brazil.
\end{abstract}

Keywords: biodiversity, Dinophyceae, Prorocentrum, Protoperidinium, Southwest Atlantic.

ISLABÃO, C.A. \& ODEBRECHT, C. Dinoflagelados (Peridiniales, Prorocentrales) do microplâncton na plataforma continental e talude do extremo sul do Brasil (inverno 2005, verão 2007). Biota Neotrop. 11(3): http://www.biotaneotropica.org.br/v11n3/pt/abstract?article+bn02511032011

Resumo: Este estudo teve por objetivo identificar as morfo-espécies de dinoflagelados do microplâncton $(>20 \mu \mathrm{m})$ das Ordens Peridiniales e Prorocentrales ao largo do Cabo de Santa Marta Grande, CSMG (SC, 28 40' S) e Albardão-Chuí, AC (RS, 34 40’ S) durante dois cruzeiros oceanográficos: inverno de 2005 e verão de 2007. Amostras de plâncton foram coletadas através de arrastos verticais com rede de plâncton $(20 \mu \mathrm{m})$, preservadas com formalina $4 \%$ e analisadas ao microscópio invertido equipado com câmara digital. Quando necessário, a identificação de espécies de Peridiniales foi efetuada através do número e morfologia das placas da teca realçadas com Calco Flúor Branco MR2; espécies de Prorocentrales foram identificadas com base em seu tamanho, forma, presença de processos apicais, padrão dos poros e marcas na faixa intercalar. Foram identificadas 25 espécies, das quais Protoperidinium (11), Prorocentrum (6), Corythodinium (3), Podolampas (2), Oxytoxum (2) e Heterocapsa (1). Espécies de Prorocentrum apresentaram ampla distribuição na plataforma continental do extremo sul do Brasil, enquanto as espécies de Peridiniales foram observadas principalmente na região do Albardão-Chuí durante o inverno, sob a influência da Pluma do Río de la Plata. Oxytoxum milneri foi pela primeira vez registrada na região sul do País, e Protoperidinium cassum var. cassum, P. curtipes e Heterocapsa triquetra foram registradas pela primeira vez no Brasil.

Palavras-chave: biodiversidade, Dinophyceae, Prorocentrum, Protoperidinium, Atlântico Sudoeste. 


\section{Introdução}

Os dinoflagelados são organismos unicelulares presentes em todas as latitudes, mais diversos e abundantes em águas marinhas tropicais e subtropicais. Aproximadamente metade das espécies pertence ao protozooplâncton, poucas são estritamente autotróficas, e muitas delas mixotróficas capazes de produção fotossintética e fagotrófica (Taylor 1987). Os dinoflagelados das Ordens Prorocentrales e Peridiniales, revestidos por parede de celulose, são frequentemente abundantes no plâncton (Reviers 2006).

A Ordem Prorocentrales é representada por um único gênero, Prorocentrum Ehrenberg, com a espécie tipo Prorocentrum micans. Todas as espécies conhecidas possuem cloroplastos e diferenciamse pelo tamanho, forma, presença de processos apicais, forma da área periflagelar, número de placas na área periflagelar, número e tamanho das aréolas e poróides, padrão dos poros e marcas na faixa intercalar (Steidinger \& Tangen 1995). Várias espécies planctônicas formam extensas florações, e existem relatos de danos à flora e/ou fauna causados por algumas delas (P. balticum, P. micans e P. minimum) (Faust et al. 1999, Uchida 1977). Entre as espécies bentônicas, existem várias espécies produtoras de toxinas (Faust et al. 1999). No cone Sul Americano, espécies de Prorocentrum são muito frequentes em águas costeiras, colorindo a água e constituindo importante fonte de alimento para pequenos invertebrados e protistas planctófagos. Frequentemente, são acompanhadas de espécies tóxicas e, por esta razão lhes foi atribuída uma toxicidade não documentada (Sar et al. 2002). Na plataforma continental do extremo sul do Brasil, foram citadas onze espécies em um levantamento realizado na década de noventa, das quais sete planctônicas, $P$. compressum, $P$. dentatum, $P$. gracile, $P$. micans, $P$. minimum, $P$. rostratum e $P$. scutellum (Seeliger et al. 1998).

Dinoflagelados da Ordem Peridiniales, com sulco e cíngulo definidos, incluem o maior número de gêneros e espécies. As principais características morfológicas que servem de critério para separar as famílias e gêneros de Peridiniales são a forma celular, disposição do cíngulo e o padrão de tamanho e localização de suas placas celulósicas de revestimento. Em alguns gêneros, especialmente Protoperidinium Bergh, o cíngulo é formado por um número variável de placas (3-12) e, aproximadamente na linha média da face ventral, a primeira placa apical (1'), não se conecta diretamente com a placa do poro Po, pois está separada por outra placa $X$, nem sempre evidente e em alguns casos atrofiada. A hipoteca apresenta quase sempre duas séries de placas características, uma que rodeia o cíngulo (pós-cingular), e a seguinte que não toca o cíngulo e contorna a parte posterior e lateral do sulco (0-3 placas). Em algumas espécies, as placas antiapicais formam processos na região posterior da célula. O sistema de classificação tradicional do gênero Protoperidinium descrito em Balech (1988) e baseado na combinação da forma da placa 1' e da placa 2a, é geralmente suportado por filogenias com base na constituição molecular (Yamaguchi et al. 2006).

Apesar da importância dos dinoflagelados, a documentação das espécies na região do extremo sul do Brasil ainda é escassa, destacando-se os estudos sobre dinoflagelados do microplâncton na região de Tramandaí (Kremer e Rosa 1983), sobre as ordens Prorocentrales (Islabão 2008), Dinophysiales (Haraguchi \& Odebrecht 2010, Haraguchi 2010), sobre o gênero Neoceratium (Pedroso 2010) e sobre Gyrodinium aureolum (Rosa \& Buselato 1981). O presente trabalho tem por objetivo aprofundar o conhecimento sobre a biodiversidade dos dinoflagelados do microplâncton e sua relação com as condições oceanográficas nesta região, com ênfase na identificação das espécies de Prorocentrales e Peridiniales.

\section{Material e Métodos}

\section{1. Área de estudo}

A plataforma continental entre o Cabo de Santa Marta Grande, CSMG (28 40' S) e Albardão-Chuí, AC (34 40' S) (Figura 1) apresenta uma largura entre $100-180 \mathrm{~km}$ e pequena declividade $\left(2 \mathrm{~m} \mathrm{~km}^{-1}\right)$ (Calliari 1998). A área ao largo da margem continental é influenciada por diversas massas de água como a Água Tropical (AT) da Corrente do Brasil, a Água Central do Atlântico Sul (ACAS), também denominada de Água Subtropical (AST), e o ramo costeiro da corrente das Malvinas, que transporta Água Sub-Antártica (ASA). As propriedades termohalinas da água na plataforma continental variam em consequência do volume de água doce descarregado pela pluma do Río de la Plata (PRP) e da Lagoa dos Patos, e do grau de influência da AT e da ASA. Assim, podem ser encontradas na região de estudo: Água Subtropical de Plataforma (ASTP), Água Sub-antártica de Plataforma (ASAP), Água Tropical (AT), Água Costeira ou Pluma do Río de la Plata (PRP) e Água Central do Atlântico Sul (ACAS) (Möller et al. 2008)

\section{Amostragem}

As amostras de plâncton foram obtidas no âmbito do Programa Núcleos de Excelência - PRONEX (Universidade Federal do Rio Grande - FURG). Foram realizados dois cruzeiros oceanográficos, o primeiro no inverno de 2005 e o segundo no verão de 2007, com 33 e 34 estações oceanográficas, respectivamente, localizadas na plataforma continental e talude do extremo sul do Brasil, em três transectos mais ao norte, ao largo do Cabo de Santa Marta Grande (estações 1-15) e ao sul, ao largo de Albardão-Chuí (estações 16-33) (Figura 1). As amostragens foram realizadas com rede (malha de 20 um; diâmetro $33 \mathrm{~cm}$; comprimento $1,10 \mathrm{~m}$ ) através de arrastos verticais (15 a 100 m) e preservadas com solução de formaldeído (4\%) neutralizada com hexamethylentetramina. Os dados de temperatura e salinidade foram obtidos através de leituras em perfis verticais, utilizando-se instrumento CTD Sea-Bird Eletronics (SBE), modelo 19E e cedidos pelo Prof. Dr. Osmar Möller para o presente estudo.

\section{Identificação de espécies}

A identificação de espécies de dinoflagelados do microplâncton ( $>20 \mu \mathrm{m}$ ) das ordens Peridiniales e Prorocentrales foi efetuada em câmara de Utermöhl e/ou entre lâmina e lamínula, com base em trabalhos clássicos como os de Schiller (1933), Taylor (1987), Balech (1988), Fukuyo et al. (1990), Sournia et al. (1991), Steidinger \& Tangen (1995), Bérard-Therriault et al. (1999), Faust \& Gulledge (2002), Hoppenrath et al. (2009) e de publicações específicas. A nomenclatura adotada seguiu basicamente o estudo de Balech (1988), sendo que a sinonímia completa é fornecida por Gómez (2005). A identificação das espécies de Peridiniales foi efetuada através do número e morfologia das placas da teca realçadas com o fluorocromo Calco Flúor Branco MR2 ${ }^{\circledR}$, específico para a celulose (Fritz \& Triemer 1985), e observadas ao microscópio de epifluorescência invertido Zeiss Axiovert $135^{\circledR}$ em aumento de 400x e/ou Zeiss Axioplan ${ }^{\circledR}$ em aumento de $1000 \mathrm{x}$, equipados com filtro de excitação ultra-violeta. Os organismos identificados foram medidos quanto ao seu comprimento total (CT), comprimento (C) e diâmetro (D). O sistema utilizado para interpretar a disposição das placas presentes em Peridiniales seguiu os critérios de Balech (1988). Os números presentes nas pranchas de imagens das espécies de dinoflagelados correspondem à placa, numerada do centro em direção ao lado esquerdo da célula de cada série: placas apicais ('), pré-cingulares ('), pós-cingulares (',') e antiapicais (","). As placas intercalares da epiteca são indicadas com a letra a como expoente, as terminologias quadra, penta ou 


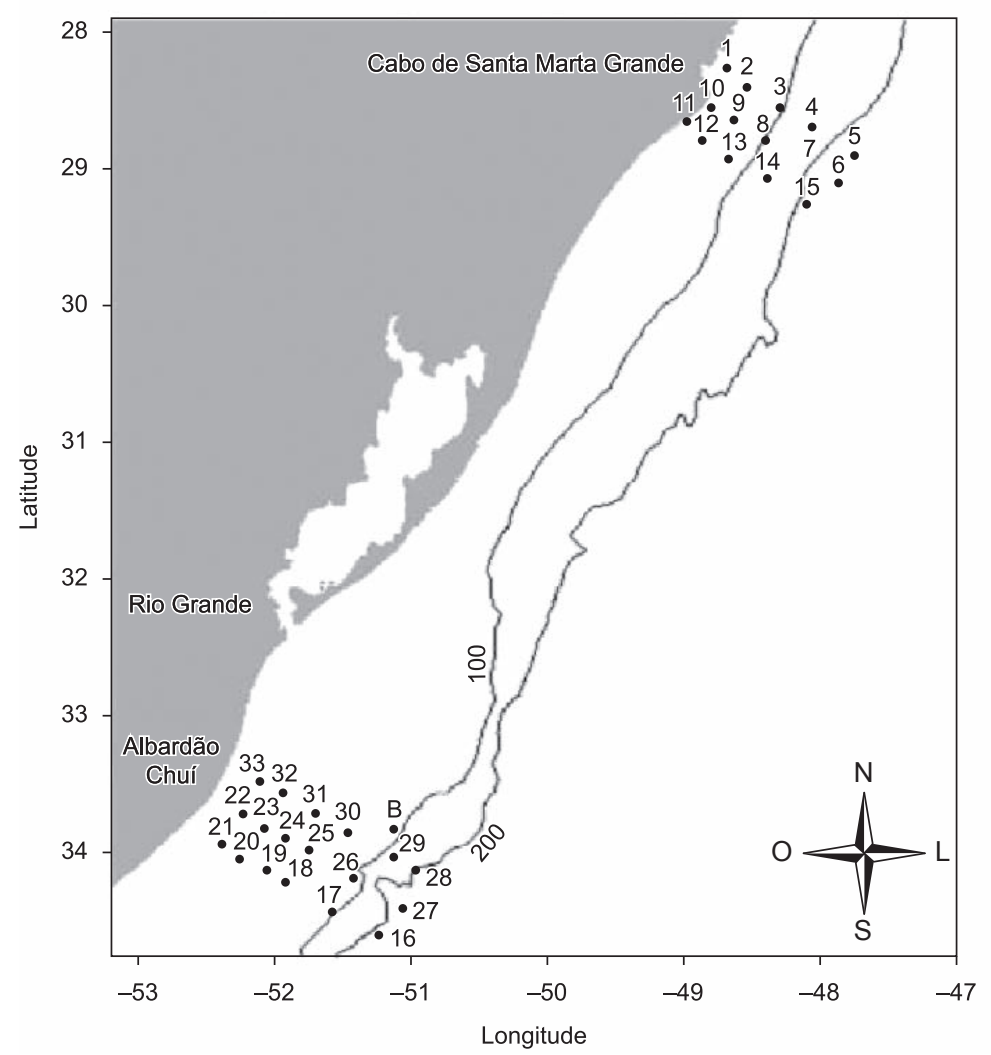

Figura 1. Área de estudo no extremo Sul do Brasil.

Figure 1. Study area in Southem Brazil.

hexa referem-se à $2 \mathrm{a}$ em relação às demais placas dorsais. As terminologias Ortho, Meta e Para referem-se à tabulação ventral, mais especificadamente, a relação da placa apical 1', com as demais.

As espécies de Prorocentrales foram identificadas com base em seu tamanho, forma, presença de processos apicais, padrão dos poros e marcas na faixa intercalar. A documentação das imagens deu-se com o uso de câmara digital Diagnostics Spot Insight ${ }^{\circledast}$, acoplada ao microscópio Axiovert, e utilização do programa Spot Basic ${ }^{\circledR}$. No microscópio Axioplan, foi utilizada uma câmara CCD Watec ${ }^{\circledR}$ e o programa IC Capture $2.0^{\circledR}$.

\section{Resultados}

\section{Descrição e distribuição das espécies}

Foram identificadas vinte e cinco espécies de dinoflagelados, entre as quais Protoperidinium (11), Prorocentrum (6), Corythodinium (3), Podolampas (2), Oxytoxum (2) e Heterocapsa (1). Destas, Heterocapsa triquetra, Protoperidinium cassum var. cassum e Protoperidinium curtipes têm seu primeiro registro no Brasil e Oxytoxum milneri na região sul. Segue a descrição das espécies identificadas, seu tamanho e distribuição.

Prorocentrum compressum (Bailey) Abe ex Dodge (Figura 2-4)

Sinônimo: Exuviaella oblonga Schiller; Exuviaella elongata Rampi

Células ovóides com a região anterior achatada. Foram encontrados organismos com uma faixa intercalar estriada bem desenvolvida, e na maioria, observado um par de processos na região anterior da célula, simétricos ou assimétricos. Em alguns foi possível observar a presença de poros irregularmente distribuídos na superfície, os centrais maiores do que os marginais.

Tamanho: C: $32-48 \mu \mathrm{m}$; D: 24-40 $\mu \mathrm{m}$. Os limites de tamanho da espécie estão dentro dos citados por Scott \& Marchant (2005) e Tenenbaum (2006), mas inferiores aos registrados por (Balech 1988).

Distribuição: Foi comumente observada em amostras da região nerítica e oceânica do CSMG e AC do verão em temperatura de $14,4-26,3{ }^{\circ} \mathrm{C}$ e salinidade de 32,6-36,9 e inverno em temperatura de $12,2-22,7^{\circ} \mathrm{C}$ e salinidade de $26,5-36,9$. Trata-se de uma espécie cosmopolita de águas frias temperadas até tropicais, nerítica e oceânica (Steidinger \& Tangen 1995), registrada no Oceano Atlântico Sudoeste por Balech (1988) desde aproximadamente $32{ }^{\circ} \mathrm{S}$ até o limite sul da Convergência Antártica com uma clara preferência por águas subantárticas $\left(11-6^{\circ} \mathrm{C}\right)$, e mais raramente encontrada em temperatura superior a $15{ }^{\circ} \mathrm{C}$, diferentemente do que foi observado neste estudo. Balech observou ainda maior abundância da espécie em estações com salinidade entre 33,7 e 34,2 .

\section{Prorocentrum gracile (Schütt) (Figura 5-7)}

Sinônimo: P. sigmoides Böhm; P. diamantinae Wood

A espécie tem forma piriforme, com a largura da célula geralmente menor que a metade de seu comprimento. Algumas células podem ser ligeiramente truncadas no pólo anterior onde junto à área periflagelar há um espinho longo com membrana e na maioria das vezes, são pontudas na extremidade posterior 
que pode ainda apresentar um pequeno dente (mucron), como registrado por Cohen-Fernandez et al. (2006). Possui dois cloroplastos laterais (Cardoso 1998). As valvas apresentam poros circulares e depressões, distribuídos por toda a superfície, aparentemente sem um padrão de distribuição. Numerosos poros alongados são encontrados do centro para a região posterior da célula.

Optamos em agrupar as formas de $P$. sigmoides como $P$. gracile, seguindo os resultados de Cohen-Fernandez et al. (2006), que demonstraram a dificuldade de diferenciar essas duas espécies.

Tamanho: C: 48-66 $\mu \mathrm{m}$; D: 16-32 $\mu \mathrm{m}$; Espinho apical: 8-16 $\mu \mathrm{m}$. As medidas tomadas neste estudo estão de acordo com os resultados para $P$. gracile no estudo de Cohen-Fernandez et al. (2006).

Distribuição: Foi a espécie mais frequente nas amostras de verão, exceto na estação 16 (AC), encontrada em temperatura de $14,4-26,3{ }^{\circ} \mathrm{C}$ e salinidade de $32,6-37$. Foi pouco observada durante o inverno em AC, mas em CSMG também ocorreu em ampla faixa de temperatura de $12,6-18,2{ }^{\circ} \mathrm{C}$ e salinidade de 31,8 35,2 . São tratadas como um complexo de espécies $P$. gracile e $P$. sigmoides junto com $P$. micans pela sua similaridade (Cohen-Fernandez et al. 2006). Estudos da morfologia externa com amostras naturais e cultivos indicaram uma distinção clara entre os morfotipos P. micans e P. gracile - P. sigmoides, entretanto não foram encontrados pelos autores características que possibilitassem a distinção convincente entre os dois últimos. O presente trabalho reforça a proposta feita por Dodge (1975) e Cohen-Fernandez et al. (2006) de que as duas sejam consideradas como sinônimo com prioridade do primeiro. A espécie apresentou a maior variação de medidas, com limites mínimo e máximo de comprimento, largura e do espinho apical, abaixo e acima daqueles reportados na literatura (Dodge 1975, Balech 1988, Behárd-Terriault et al. 1999). O agrupamento dos organismos mais característicos de $P$. sigmoides (tamanho maior, valva sigmóide e espinho robusto) com $P$. gracile influenciou estas medidas.

\section{Prorocentrum micans (Ehrenberg) (Figura 8-10)}

Sinônimo: Prorocentrum Schilleri Bohm in Schiller; P. gibbosum Schiller

As células têm forma piriforme e possuem um espinho apical bem desenvolvido, que quando presente é menor de que em $P$. gracile. A superfície valvar é marcada por poros, organizados em fileiras curtas, perpendiculares à margem. A largura da célula geralmente corresponde à metade do comprimento (razão C: LA geralmente <2), mas nem sempre esta relação é observada, algumas células apresentaram a largura maior ou menor que a metade do comprimento, como também observado por Balech (1988). As células possuem dois cloroplastos periféricos em forma de placa contendo um pirenóide grande (Cardoso 1998). A valva possui poros de tamanho grande, localizados principalmente na região apical e antapical e de tamanho pequeno que normalmente diminuem em direção às margens, além de depressões cobrindo o resto da valva (Cohen-Fernandez et al. 2006).

Tamanho: C: 32-64 $\mu \mathrm{m}$; D: 16-32 $\mu \mathrm{m}$; Espinho apical: 8-10 $\mu \mathrm{m}$.

Distribuição: Observada principalmente no verão em $\mathrm{AC}$, em ampla faixa de temperatura de $14,4-26,1{ }^{\circ} \mathrm{C}$ e de salinidade de 32,7-37. No inverno, observada principalmente em AC, em temperatura de $12,9-21,4{ }^{\circ} \mathrm{C}$ e salinidade de $26,5-36,6$; no CSMG em temperatura de $17,7-21,4{ }^{\circ} \mathrm{C}$ e salinidade de 33,1 36,6. P. micans apresenta ampla distribuição em águas quentes, mais frequente em águas neríticas que oceânicas (Balech
1988). A espécie forma extensas florações, sendo responsável pela excreção de uma substância inibidora ao crescimento das diatomáceas Skeletonema costatum e Chaetoceros didymus (Uchida 1977).

Prorocentrum minimum (Pavillard) Schiller (Figuras 11 e 12)

Sinônimo: Prorocentrum mariae-lebourae (Parke et Ballantine) Loeblich; P. cordatum (Ostenfeld) Dodge

As células são muito pequenas, de contorno cordiforme a triangular. Alguns indivíduos apresentavam contorno mais arredondado e outros mais triangular. Presença de uma pequena projeção apical.

Tamanho: C: $13-17 \mu \mathrm{m}$; D: 11-14 $\mu \mathrm{m}$.

Distribuição: A espécie ocorreu somente na região do AC durante os dois períodos: no inverno, observada em duas estações (temperatura $12,3-17,1{ }^{\circ} \mathrm{C}$; salinidade $28,2-34,5$ ) e em três estações no verão (temperatura $15,3-25,0{ }^{\circ} \mathrm{C}$; salinidade 33,1-34,9). Esse resultado pode estar subestimado pela possível perda de organismos durante a coleta já que seu tamanho é menor do que a porosidade da malha da rede $(20 \mu \mathrm{m})$, e a dificuldade de visualizá-los nas amostras. Algumas células apresentaram os limites de comprimento inferiores aos reportados por Hoppenrath et al. (2009) (17-24 $\mu \mathrm{m})$ e por Lu et al. (2005) (C: 15-23 $\mu \mathrm{m}$; D: 10-15 $\mu \mathrm{m})$. Esta espécie é mixotrófica, euritérmica (temperatura $4-31{ }^{\circ} \mathrm{C}$ ) e eurihalina (salinidade 5-37), mas suas florações ocorrem com maior frequência em águas salobras (Faust et al. 1999). Foi encontrada em alta concentração no estuário da Lagoa dos Patos, no outono e inverno de 1991, associado à estabilidade da coluna de água e ao fluxo contínuo de nutrientes (Persich 1993). P. minimum foi apontado como responsável por envenenamentos causados pelo consumo de ostras e mexilhões em seis eventos de intoxicação no Japão, com 185 casos fatais ( $34 \%$ dos casos). A venerupina, provável toxina, não teve ainda elucidada a sua estrutura química nem propriedades, e as observações e experimentos em laboratório não permitiram confirmar que $P$. minimum fosse o produtor da toxina. A espécie não é considerada persistentemente tóxica (Hallegraeff et al. 2004), mas suas culturas senescentes podem produzir toxinas e toxicidade, sendo considerada responsável pela morte de crustáceos no Japão e no Golfo do México (Faust et al. 1999).

\section{Prorocentrum rostratum (Stein) (Figura 13)}

\section{Sinônimo: Prorocentrum styliferum Lohmann; P. tenue Lohmann}

Células alongadas, com um rostro proeminente na parte anterior e afiladas na região posterior. Presença de uma faixa intercalar aparente. A forma típica desta espécie permite facilmente a sua identificação.

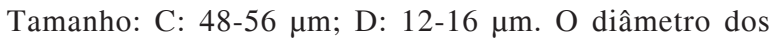
organismos medidos foi superior ao indicado por Dodge (1975).

Distribuição: Observada em AC e CSMG durante o verão em temperatura de $14,5-26,2{ }^{\circ} \mathrm{C}$; e salinidade de $33,1-37,0$. No AC, somente durante o inverno em temperatura de $13,2-20,3{ }^{\circ} \mathrm{C}$ e salinidade de 34,6-36,5 (Tabela 1). É uma espécie de ampla distribuição, nerítica e de águas quentes (Steidinger \& Tangen 1995).

\section{Prorocentrum scutellum (Schöder) (Figura 14-16)}

\section{Sinônimo: P. sphaeroideum Schiller; P. robustum Tafall}

As células são geralmente cordiformes, tendendo a subcirculares ou ovóides, com duas projeções apicais assimétricas na região 
anterior da valva esquerda. Poros distribuídos em fileiras perpendiculares a borda, os centrais sendo maiores.

Tamanho: C: 30-48 $\mu \mathrm{m}$; D: 24-46 $\mu \mathrm{m}$. As medidas de comprimento e largura foram um pouco inferiores do que aquelas citadas por Yamaji (1984) e Dodge (1975).

Distribuição: Observada em CSMG e AC em ambos os cruzeiros (Tabela 1), em ampla faixa de temperatura de 12,2$26,3{ }^{\circ} \mathrm{C}$ e salinidade $26,5-37,9$. A espécie pode eventualmente ser confundida com $P$. compressum, mas de modo geral a distinção entre as duas é clara, devido principalmente a sua forma cordiforme e presença de projeções apicais assimétricas, uma delas marcadamente mais larga na base. É uma espécie nerítica ou estuarina que ocorre desde o Ártico até águas tropicais (Steidinger \& Tangen 1995).

Tabela 1. Presença das espécies de Prorocentrum e Peridiniales ao largo do Albardão-Chuí (AC) e Cabo de Santa Marta Grande (CSMG), durante os cruzeiros de inverno de 2005 e verão de 2007.

Table 1. Presence of Prorocentrum and Peridiniales species off AlbardãoChuí (AC) and Santa Marta Grande Cape (CSMG), during the winter 2005 and summer 2007 cruises.

\begin{tabular}{|c|c|c|c|c|}
\hline \multirow[t]{2}{*}{ Espécies } & \multicolumn{2}{|c|}{ Inverno } & \multicolumn{2}{|c|}{ Verão } \\
\hline & $\mathrm{AC}$ & CSMG & AC & CSMG \\
\hline \multicolumn{5}{|l|}{ Prorocentrum } \\
\hline P. compressum & $\mathrm{x}$ & $\mathrm{x}$ & $\mathrm{x}$ & $\mathrm{x}$ \\
\hline P. gracile & $\mathrm{x}$ & $\mathrm{x}$ & $\mathrm{x}$ & $\mathrm{x}$ \\
\hline P. micans & $\mathrm{x}$ & $\mathrm{x}$ & $\mathrm{x}$ & $\mathrm{x}$ \\
\hline P. minimum & $\mathrm{x}$ & - & $\mathrm{x}$ & - \\
\hline P. rostratum & $\mathrm{x}$ & - & $\mathrm{x}$ & $\mathrm{x}$ \\
\hline P. sutellum & $\mathrm{x}$ & $\mathrm{x}$ & $\mathrm{x}$ & $\mathrm{x}$ \\
\hline \multicolumn{5}{|l|}{ Protoperidinium } \\
\hline P. depressum & $\mathrm{x}$ & $\mathrm{x}$ & - & - \\
\hline P. divaricartum & $\mathrm{x}$ & - & - & - \\
\hline P. oceanicum & $\mathrm{x}$ & - & - & - \\
\hline P. obtusum & $\mathrm{x}$ & - & - & - \\
\hline P. pentagonum & $\mathrm{x}$ & $\mathrm{x}$ & $\mathrm{x}$ & - \\
\hline P. cassum var. cassum & $\mathrm{x}$ & $\mathrm{x}$ & - & - \\
\hline P. curtipes & $\mathrm{x}$ & - & - & - \\
\hline P. divergens & $\mathrm{x}$ & $\mathrm{x}$ & $\mathrm{x}$ & - \\
\hline P. cf. parviventer & $\mathrm{x}$ & - & $\mathrm{x}$ & $\mathrm{x}$ \\
\hline Protoperidinium sp. & $\mathrm{x}$ & - & - & - \\
\hline P. longipes & - & $\mathrm{x}$ & - & - \\
\hline \multicolumn{5}{|l|}{ Corythodinium } \\
\hline C. constrictum & - & - & $\mathrm{x}$ & - \\
\hline C. diploconus & - & $\mathrm{x}$ & - & - \\
\hline C. tesselatum & - & $\mathrm{x}$ & $\mathrm{x}$ & - \\
\hline \multicolumn{5}{|l|}{ Oxytoxum } \\
\hline O. milneri & - & - & $\mathrm{x}$ & - \\
\hline O. scolopax & - & $\mathrm{x}$ & - & - \\
\hline \multicolumn{5}{|l|}{ Podolampas } \\
\hline P. bipes & - & $\mathrm{x}$ & $\mathrm{x}$ & - \\
\hline P. palmipes & - & $\mathrm{x}$ & $\mathrm{x}$ & - \\
\hline \multicolumn{5}{|l|}{ Heterocapsa } \\
\hline H. triquetra & $\mathrm{x}$ & - & - & - \\
\hline
\end{tabular}

Protoperidinium depressum (Bailey) Balech (Figura 17)

Sinônimos: Peridinium parallelum (Broch); Peridinium marinum (Lindermann)

Células com a tabulação ventral da epiteca do tipo Ortho e da hipoteca do tipo Quadra. Processos bem desenvolvidos, sendo o antiapical direito geralmente mais grosso e largo, às vezes bem mais do que o esquerdo. Apresenta-se muito larga na altura do cíngulo, com achatamento dorso-ventral moderado. A escultura é frágil com poros, e às vezes, granulações. A sua identificação é relativamente fácil devido ao grande tamanho, no entanto, o alargamento da célula na altura do cíngulo dificulta a observação de toda a célula em vista ventral ou dorsal.

Tamanho: CT: 97,5-137,5 $\mu \mathrm{m}$; D: 87-130 $\mu \mathrm{m}$. O tamanho dos menores exemplares observados foi um pouco menor do que o observado por Balech (1988).

Distribuição: Espécie freqüentemente observada nas amostras do inverno de 2005 na região nerítica, principalmente na faixa de temperatura de $12,3-19,9{ }^{\circ} \mathrm{C}$ e salinidade de $28,2-36,3$. De acordo com Balech (1988), ocorre nas zonas nerítica e oceânica no Oceano Atlântico Sudoeste até a latitude de $48^{\circ} \mathrm{S}$, em ampla faixa de temperatura, salinidade e concentração de nutrientes. Ainda, apresenta uma grande variação de suas medidas, desenvolvimento dos processos e até mesmo em sua tabulação (anomalias tabulares são freqüentes), justificando a existência de vários sinônimos. É uma das poucas espécies de dinoflagelados planctônicos heterotróficos, capaz de alcançar alta abundância sazonal em estuários e águas costeiras (Steindiger \& Tangen 1995).

Protoperidium divaricatum (Meunier) nov. comb. Balech (Figura 18- 20)

Sinônimos: Peridinium divaricatum (Meunier); Protoperidinium gainii (Dangeard) Balech

Forma pentagonal, um pouco mais larga que alta, com a cavidade antiapical ampla e rasa. Chifres antiapicais incipientes, terminados em curtos espinhos divergentes, às vezes muito oblíquos para fora e sempre muito separados entre si. Tabulação ventral da epiteca do tipo Ortho. Cíngulo pouco inclinado com aletas cingulares muito estreitas. Placa 1' de largura mediana e quase simétrica, 2a do tipo Hexa bastante alta e $3{ }^{`}$ relativamente pequena.

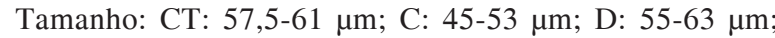
Distância entre espinhos: $27,5 \mu \mathrm{m}$

Distribuição: Observada na região nerítica do AC durante o inverno de 2005 , em temperatura de $13,2-19,8{ }^{\circ} \mathrm{C}$ e salinidade de 34,9-36,4. Os exemplares observados apresentam morfologia e tabulação idênticas aos apresentados por Balech (1988), no entanto são menores. Mais ao norte nas proximidades de Santos, a espécie apresenta tamanho maior $(80-89 \mu \mathrm{m})$ e espinhos ainda mais divergentes (Balech 1988). Este autor considera P. gainii e $P$. divaricatum como a mesma espécie, nerítica de ampla distribuição em águas quentes e temperadas até águas mais frias.

Protoperidinium oceanicum (Vanhöffen) Balech (Figura 21- 22)

Sinônimo: Peridinium oceanicum (Vanhöffen); Peridinium murrayi (Kofoid)

As células são alongadas, com processos apicais e antiapicais bem desenvolvidos. A teca apresenta certa convexidade no cíngulo, que se estende para as partes basais da epiteca e hipoteca, onde se converte em concavidade e marca o início dos processos. Processos antiapicais de comprimento mais ou menos igual, mas a separação de seus extremos pode variar. O plano 
Islabão, C.A. \& Odebrecht, C.
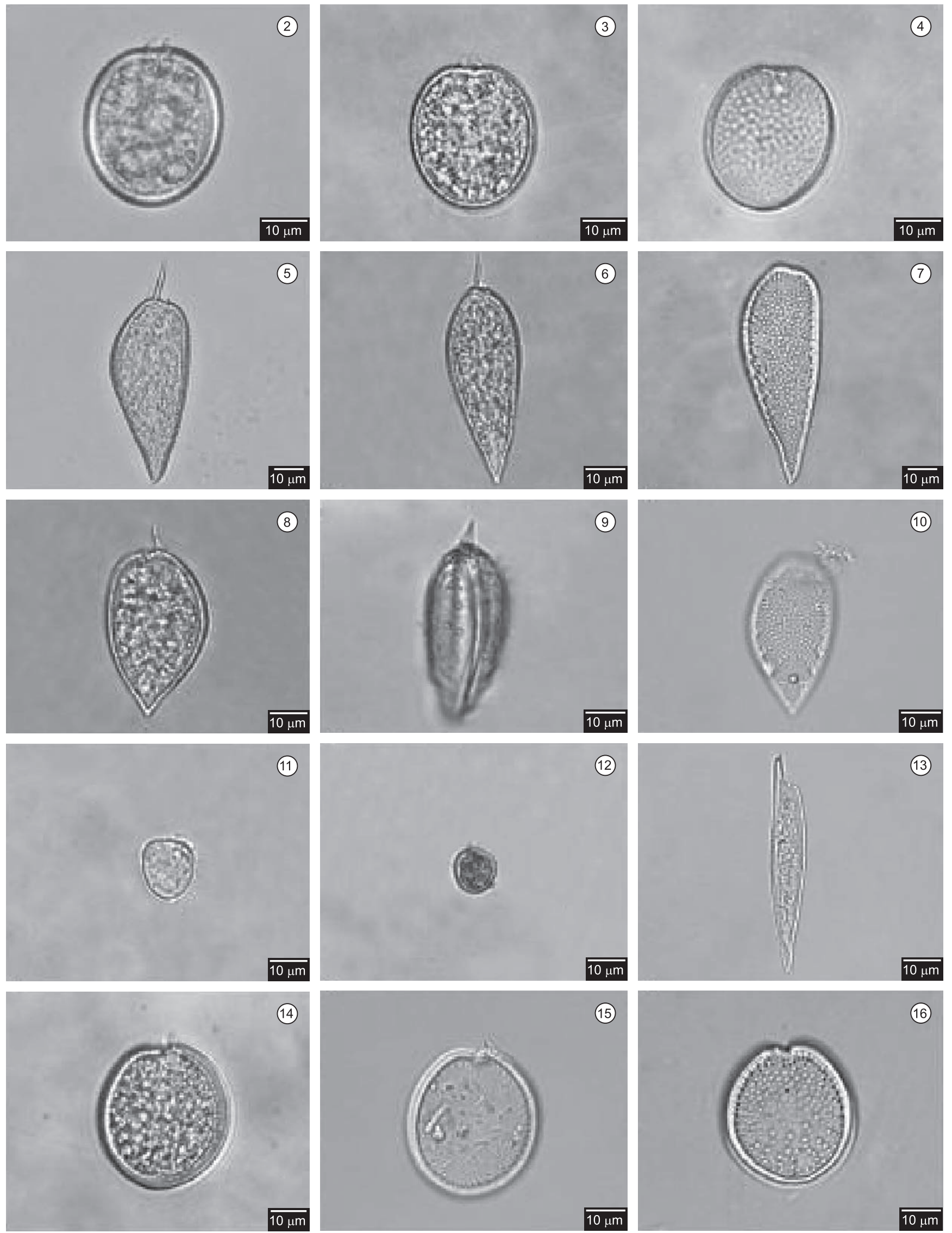

(16)
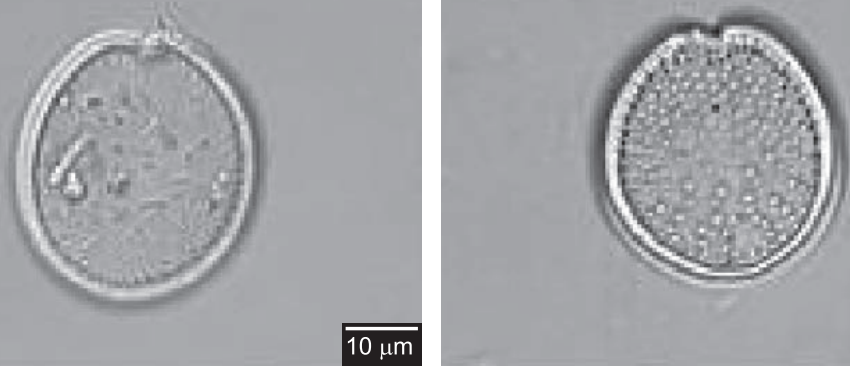

Figura 2-16. 2-4 - Procentrum compressum; 5-7 - P. gracile; 8-10 - P. micans; 11-12 - P. minimum; 13 - P. rostratum; 14-16 - P. scutellum. Escala 10 $\mu$ m. Figures 2-16. 2-4 - Procentrum compressum; 5-7 - P. gracile; 8-10 - P. micans; 11-12 - P. minimum; 13 - P. rostratum; 14-16 - P. scutellum. Scale 10 $\mu$ m. 
cingular é inclinado em relação ao eixo longitudinal da célula e descendente, limitado por aletas desenvolvidas que podem ser lisas ou com pseudoraios. O plano inclinado do cíngulo torna difícil a observação da epiteca em um mesmo plano horizontal. Escultura delicada, reticulado irregular com poros visíveis. Tabulação ventral da epiteca do tipo Ortho. Em geral, é uma espécie de fácil identificação.

Tamanho: CT: $130 \mu \mathrm{m}$; C: $95 \mu \mathrm{m}$; D: $70 \mu \mathrm{m}$.

Distribuição: Observada na plataforma do AC durante o inverno em temperatura de $12,5-12,9^{\circ} \mathrm{C}$ e salinidade de 30,8-30,9. Por ser uma espécie de ampla distribuição, apresenta variações no tamanho, comprimento dos processos e na tabulação (número de intercalares e tabulação ventral do tipo Para). Por esta razão foram criadas muitas formas e variedades (Balech 1988). Para alguns autores, essa forma é designada $P$. oblongum, que também pode ter o chifre apical curto e mal delimitado. Apesar deste último ser um táxon muito discutido, é aceito como variedade de P. oceanicum (Balech 1988).

Protoperidinium obtusum (Karsten) Balech (Figura 23- 24)

\section{Sinônimo: Peridinium obtusum (Karsten)}

Células de forma pentagonal com a cavidade antiapical não muito profunda. Geralmente há pouca diferença entre a largura e comprimento dos exemplares. Tabulação ventral da epiteca do tipo Ortho e dorsal do tipo Hexa. Os dois processos antiapicais curtos e grossos terminam em pequenos espinhos. Plano cingular oblíquo com membranas cingulares muito estreitas. A placa 1' é larga com o triângulo anterior curto. Células com escultura forte e predominância de linhas verticais sinuosas. Linhas vermiformes, irregulares e granulação também são observadas. Em vista lateral, apresenta acentuado achatamento dorso-ventral. É geralmente de fácil reconhecimento por sua morfologia geral, forte inclinação do cíngulo, forma da placa 1', cor escura e escultura da célula.

Tamanho: C: 70-75 $\mu \mathrm{m}$; D: 70-77,5 $\mu \mathrm{m}$.

Distribuição: Observada durante o inverno de 2005 na região nerítica do AC, em temperatura de $12,5-16,0{ }^{\circ} \mathrm{C}$ e salinidade de 26,5-33,9. Parece preferir águas temperadas-frias, comumente observada na faixa de temperatura de $9-20{ }^{\circ} \mathrm{C}$, registros com mais de $17{ }^{\circ} \mathrm{C}$ são raros (Balech 1988).

\section{Protoperidinium pentagonum (Gran) Balech (Figura 25-26)}

\section{Sinônimo: Peridinium pentagonum (Gran)}

As células são grandes, pentagonais, mais largas do que altas. Sem pescoço, com chifres antiapicais curtos e relativamente largos, terminando em espinhos divergentes. Tabulação ventral da epiteca do tipo Ortho, com a placa 1' longa, e dorsal do tipo Hexa. Forte achatamento dorso-ventral, com uma cavidade na região ventral central da célula, para onde se direcionam suas laterais. Cíngulo escavado, contornado por largas aletas e com certa tendência ao entrecruzamento.

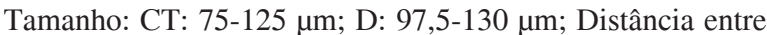
espinhos: 37,5-55 $\mu \mathrm{m}$.

Distribuição: Observada em amostras dos dois períodos, na plataforma continental do AC e CSMG no cruzeiro de inverno (temperatura $12,7-31,3{ }^{\circ} \mathrm{C}$; salinidade $29,9-36,6$ ), e na região costeira de $\mathrm{AC}$ no cruzeiro de verão (temperatura $18,4-21,8^{\circ} \mathrm{C}$; salinidade 35,4-35,9). Esta espécie apresenta uma forma característica com a curvatura e projeção dos extremos laterais do cíngulo para a região ventral central da célula. Segundo Balech (1988), é termófila de águas neríticas e oceânicas com uma tolerância que permite a sobrevivência em águas mais frias, mas raramente observada em temperatura inferior a $14{ }^{\circ} \mathrm{C}$.
Protoperidinium cassum var. cassum Balech (Figura 27- 28)

\author{
Sinônimo: Peridinium cassum Balech
}

Células de forma piriforme. Longos espinhos antiapicais, um pouco divergentes, rodeados por membranas aparentes. Tabulação ventral da epiteca do tipo Meta e dorsal do tipo Penta. Placa pré cingular 4" bem mais alta que a intercalar 2a.

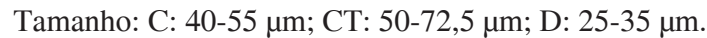

Distribuição: Observada somente no inverno, em uma estação do CSMG (estação 14) e duas do AC (estações 26 e 33), em uma faixa de temperatura de $12,9-21,4{ }^{\circ} \mathrm{C}$ e salinidade $26,5-36,6$. A espécie apresenta duas variedades, $P$. cassum var. cassum de tamanho maior (CT 60-72 $\mu \mathrm{m}$ ) do que $P$. cassum var. decens (CT 54-64 $\mu \mathrm{m}$ ), esta última de forma um pouco mais arredondada, espinhos mais divergentes e, sobretudo, apresenta a placa précingular 4" mais alta (Balech 1988). Esta última predomina em águas quentes e a primeira em águas frias, entre $59^{\circ} \mathrm{S}$ e $37^{\circ} \mathrm{S}$ no Atlântico Sul Ocidental, com alguns exemplares encontrados ao sul da convergência. Na região de estudo, foram observados exemplares típicos de $P$. cassum var. cassum, e alguns mais semelhantes a $P$. cassum var. decens, principalmente na forma da placa 4" mais alta.

\section{Protoperidinium curtipes (Jørgensen) Balech (Figura 29- 31)}

\section{Sinônimo: Perdidinium curtipes (Jørgensen)}

As células tem forma característica com seu cíngulo circular ligeiramente descendente, epiteca em linha reta ou côncava, terminada em um chifre apical robusto. Hipoteca primeiramente convexa, e então côncava até o começo dos processos antiapicais robustos. Placas tecais claramente reticuladas. A tabulação ventral da epiteca é do tipo Meta e dorsal do tipo Quadra.

Tamanho: CT: $130 \mu \mathrm{m}, \mathrm{D}: 107 \mu \mathrm{m}$. O tamanho observado foi maior do que o registrado por (Hoppenrath et al. 2009) (máximo $100 \mu \mathrm{m})$.

Distribuição: A espécie foi observada na plataforma do AC somente durante o inverno, em uma faixa de temperatura de 12,5-12,9 ${ }^{\circ} \mathrm{C}$ e salinidade de 30,8-30,9. Esta espécie pode ser confundida com $P$. crassipes, a qual é maior, mas não apresenta o chifre apical tão distinto (Hoppenrath et al. 2009). Além disto, é ainda diferenciada pela forma do corpo, placas sulcais e falta de cor no plasma, amarelado em P. curtipes (Elbrãchter 1975 apud Hoppenrath et al. 2009). Alguns autores (Schiller 1937, Peters 1928 apud Balech 1988) as consideram uma espécie e Balech (1988) não descarta a possibilidade de $P$. curtipes ser a forma de águas frias de $P$. crassipes, que seria de águas mais quentes.

Protoperidinium divergens (Ehrenberg) Balech (Figura 32- 34)

\section{Sinônimo: Peridinium divergens Ehrenberg in Müller}

As células apresentam um forte reticulado. Em vista ventral, tem forma pentagonal com uma profunda cavidade antiapical delimitada por um par de processos desenvolvidos, os quais terminam em espinhos divergentes. Os lados da epiteca são geralmente quase retos na base ou ligeiramente convexos, e mais acima forma-se uma cavidade suave de onde inicia o processo apical. A tabulação ventral da epiteca é do tipo Meta e dorsal do tipo Quadra.

Tamanho: CT: 94-117,5 $\mu \mathrm{m}$; D: 59-87 $\mu \mathrm{m}$. Alguns organismos maiores do que os registrados por Balech (1988).

Distribuição: A espécie foi observada principalmente durante o inverno na plataforma do AC em temperatura de $13,2-19,8^{\circ} \mathrm{C}$ e salinidade de 29,9-36,4, mas também ao largo do CSMG em uma única estação. Ainda, observada durante o verão na área 

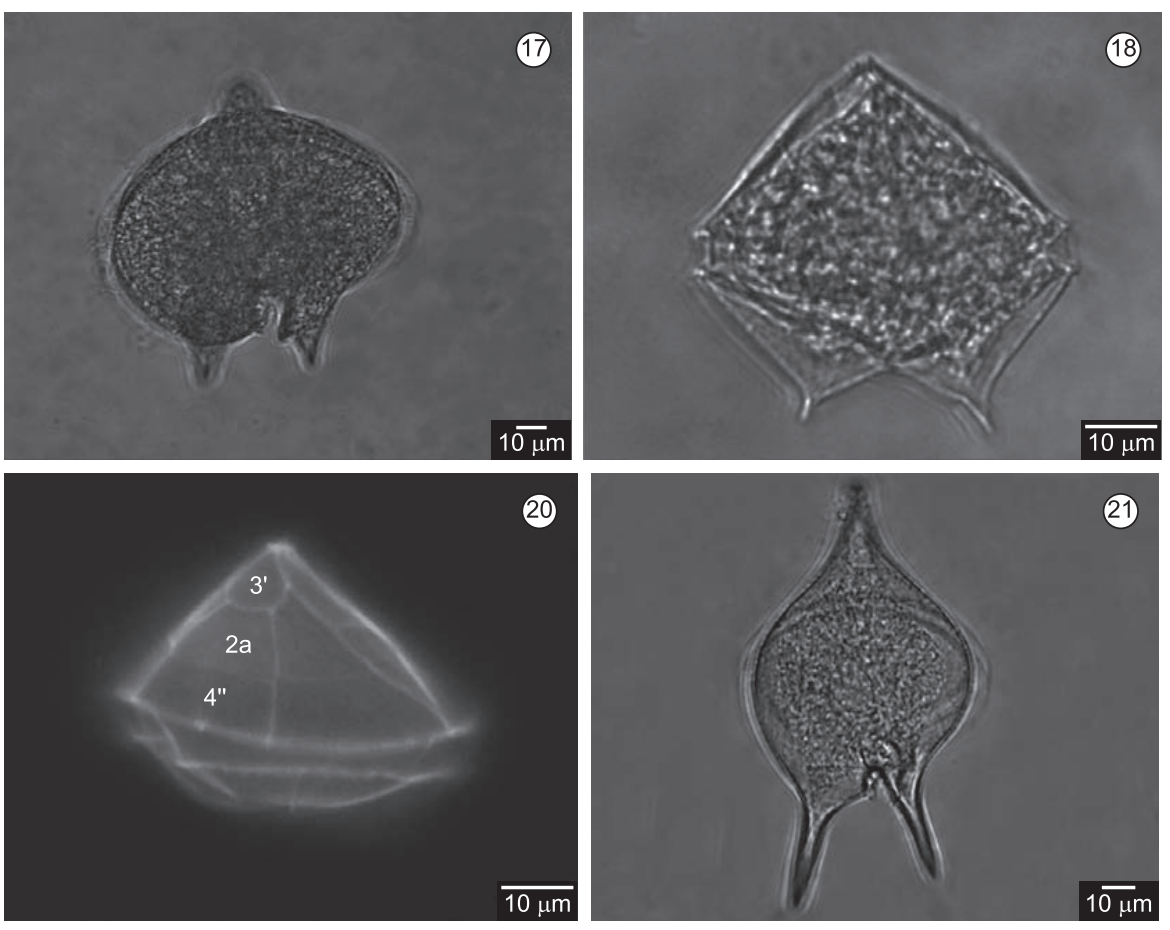

(23)
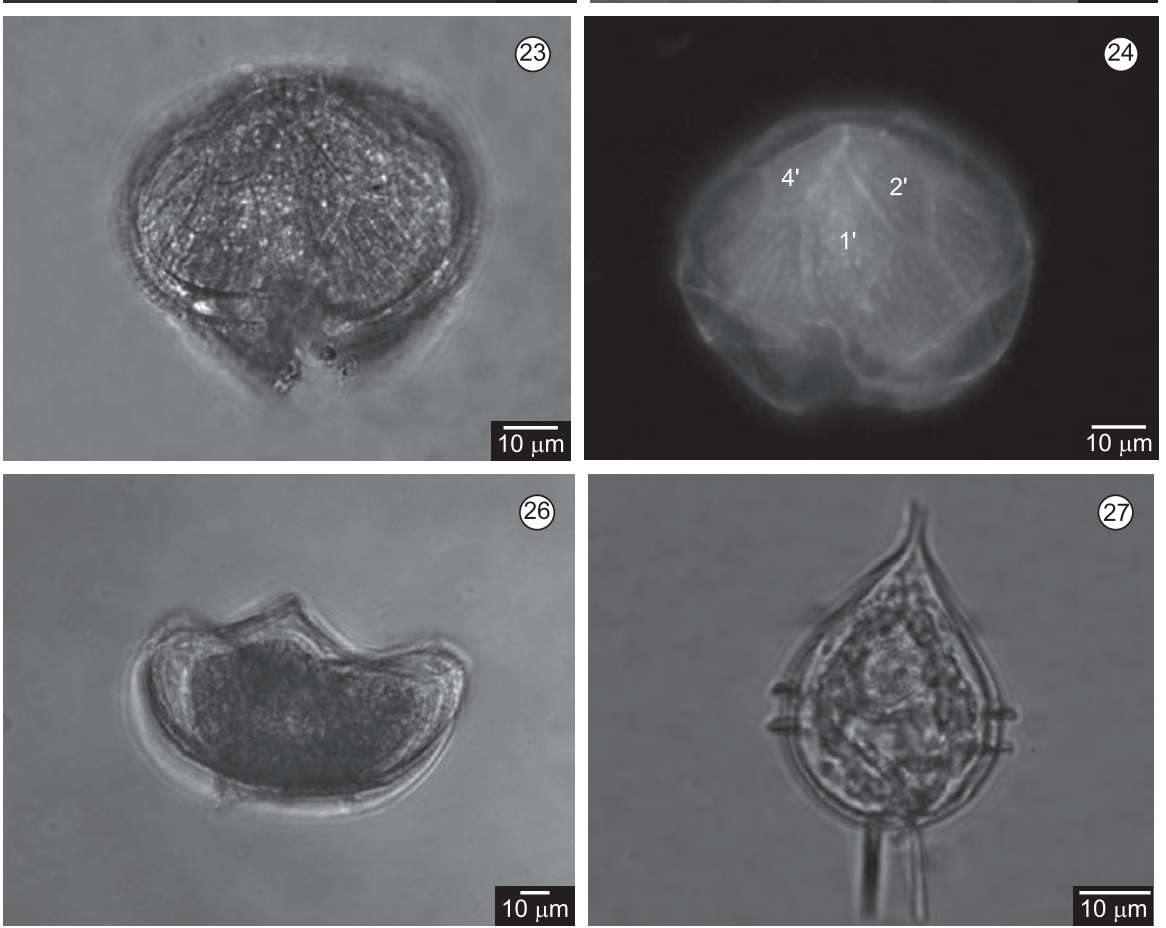

24

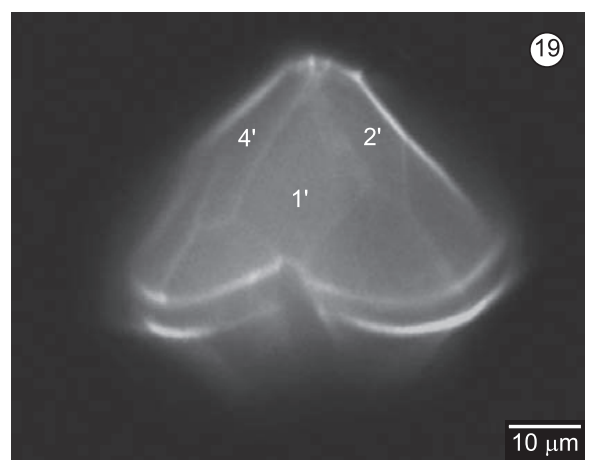

(21)
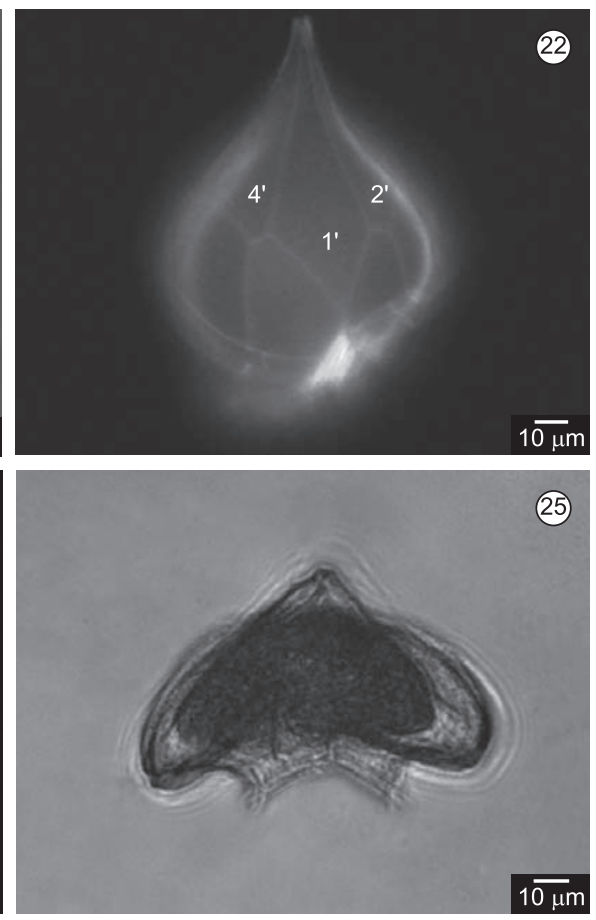

(27)

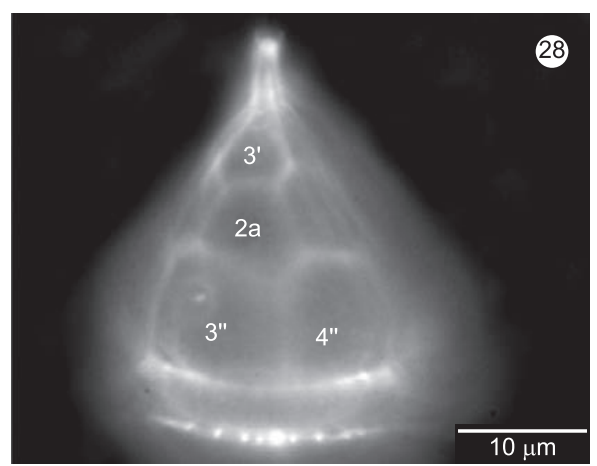

Figuras 17-28. 17 - Protoperidinium depressum; 18-20 - P. divaricatum;21-22 - P. oceanicum; 23-24 - P. obtusum; 25-26- P. pentagonum; 27-28 - P. cassum var. cassum. Escala $10 \mu \mathrm{m}$.

Figures 17-28. 17 - Protoperidinium depressum; 18-20 - P. divaricatum; 21-22 - P. oceanicum; 23-24 - P. obtusum; 25-26 - P. pentagonum; 27-28 - P. cassum var. cassum. Scale $10 \mu \mathrm{m}$.

oceânica do $\mathrm{AC}$ em temperatura de $17,6-24,0^{\circ} \mathrm{C}$ e salinidade de 33,8-35,9. É uma das espécies mais antigas e citadas do gênero, mas muitas vezes os registros seguem critérios duvidosos que dificultam o conhecimento sobre a sua ecologia e distribuição (Balech 1988). Mesmo assim, parece ser termófila tolerante, em temperatura superior a $14{ }^{\circ} \mathrm{C}$, e de ampla distribuição nos mares quentes e temperados (Balech 1988).
Protoperidinium cf. parviventer (Balech) (Figura 35- 37)

Sinônimo: Protoperidinium parviventer (Balech 1978)

Células com forma pentagonal, mais largas que longas. Epiteca termina em um processo curto, e a hipoteca mais baixa, com a cavidade antiapical delimitada por dois espinhos curtos e robustos, com membranas estreitas. Achatamento dorso-ventral 
moderado. Tabulação ventral da epiteca do tipo Meta e dorsal do tipo Quadra. No cíngulo, placas cingulares estreitas, aletas com ou sem raios. Sulco profundo. Placas intercalares bem marcadas, sendo a 2 a alta e estreita, típica de $P$. parviventer. A placa apical (1') diverge um pouco da apresentada por Balech (1988) na região de união com as placas 2', 1', e 2''. Em seu lado esquerdo, observa-se uma linha reta que parte do ápice da célula em direção a porção inferior da placa, formando um losango. $\mathrm{Na}$ figura apresentada por Balech, a linha que une a placa 1' com as placas 2' e 2" não é reta.

Tamanho: CT: 55-92 $\mu \mathrm{m}$; D: 63-72 $\mu \mathrm{m}$. O comprimento máximo $(92 \mu \mathrm{m})$ foi maior do que observado $(81 \mu \mathrm{m})$ por Balech (1988).

Distribuição: Observada principalmente na região nerítica do AC durante inverno de 2005 e verão de 2007, neste último período também foi observada na área oceânica e CSMG. No inverno, em temperatura de $12,5-18,8^{\circ} \mathrm{C}$ e salinidade de $30,8-36,3$; no verão em temperatura de $17,6-24^{\circ} \mathrm{C}$ e salinidade de $33,8-35,9$. Segundo Balech (1988) a espécie apresenta preferência por águas quentes ou temperadas-quentes e foi observada até a latitude de $42{ }^{\circ} \mathrm{S}$.

Protoperidinium sp. (Figura 38)

A célula apresenta tabulação ventral da epiteca do tipo Meta e é muito parecida com $P$. brochi, no entanto, mais globosa e com processos relativamente mais curtos, semelhante à $P$. inflatum, mas com processos antiapicais mais divergentes e união das placas 1' e 4' diferente.

Tamanho: CT: $110 \mu \mathrm{m}$; C: $93 \mu \mathrm{m}$; D: $80 \mu \mathrm{m}$. Apenas um exemplar foi observado.

Distribuição: A espécie foi observada na plataforma do AC durante o inverno, em temperatura de $12,7-16,0{ }^{\circ} \mathrm{C}$ e salinidade de 29,9-33,9. A forma mais globosa e a presença de suturas largas são similares ao desenho na Prancha 41, figura 8 apresentada por Balech (1988) como P. inflatum, no entanto, a célula era maior e os espinhos antiapicais mais divergentes, com medidas mais próximas de $P$. brochi. Considerando o tamanho observado, a divergência dos chifres antiapicais e a união das placas 1' e 4' diferente de $P$. inflatum e $P$. brochi, optamos por mantê-la como Protoperidinium sp.

Protoperidinium longipes (Karsten) Balech (Figura 39- 40)

\section{Sinônimo: Peridinium (divergens) longipes Karsten}

Corpo grande e pentagonal, com as laterais (esquerda e direita) um pouco convexas, e largura máxima na altura do cíngulo. Achatado dorso ventralmente. A epiteca é baixa e dela se estende um processo truncado mais longo do que a epiteca. Hipoteca com dois fortes e longos espinhos bem separados entre si, divergentes, mas levemente côncavos, e margeados por aletas de largura média. À esquerda da célula, a aleta da S.p (sulcal posterior) é bem visível. Aletas do cíngulo são amplas, com reforços radiais. Tabulação ventral da epiteca do tipo Para e dorsal do tipo Hexa.

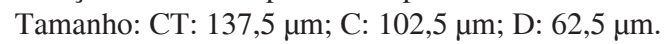

Distribuição: Observada na plataforma continental do CSMG durante o inverno, sob influência de águas tropicais (AT e ASTP) e ACAS. A temperatura $\left(17,3-21,1{ }^{\circ} \mathrm{C}\right)$ corresponde àquela registrada por Balech (1988), mas a variação da salinidade (33,8$36,5)$ foi mais ampla no presente estudo. Considerada uma espécie nerítica e termófila, na região do Atlântico Sul Ocidental ocorre até $37^{\circ} 38^{\prime} \mathrm{S}$, com preferência por águas da Corrente do Brasil (Balech 1988). Esta espécie pode ser confundida com $P$. diabolus (Cleve), que foi representada mais tarde por Pavillard (1916) e Balech (1976 apud Balech 1988), no entanto Taylor (1976 apud
Balech 1988) considera $P$. longipes uma variedade de $P$. diabolus. Segundo (Gomez 2005) P. diabolus é sinônimo de $P$. longipes (Karsten) Balech.

\section{Corythodinium constrictum (Stein) Taylor (Figura 41)}

\section{Sinônimo: Oxytoxum constrictum}

As células são de tamanho médio, com a epiteca em forma cônica-arredondada e a hipoteca obcônica apresentando uma constrição em seu terço superior, e terminando em um pequeno espinho. Cíngulo profundo e um pouco descendente.

Tamanho: CT: $50 \mu \mathrm{m}$; D: $20 \mu \mathrm{m}$; Altura da epiteca: 7,5 $\mu \mathrm{m}$; Largura maior da hipoteca: $22,5 \mu \mathrm{m}$. O tamanho do exemplar medido foi menor do que o dos indivíduos registrados por Balech (1988) e Tenenbaum (2006).

Distribuição: Observada somente durante o verão na plataforma do AC em temperatura de $16,6-24,2^{\circ} \mathrm{C}$ e salinidade de 33,5-36,6. Considerada uma espécie termófila, pouco observada no sul do Brasil (Balech 1988).

\section{Corythodinium diploconus (Stein) Balech (Figura 42- 43)}

Sinônimo: Oxytoxum diploconus (Stein) Schütt; Corythodinium diploconus (Stein) Taylor

Células de tamanho médio, com epiteca terminada em um cone apical com a base larga e a extremidade pontiaguda. Hipoteca cônico-convexa terminada em um pequeno espinho às vezes pouco diferenciado. Cíngulo profundo e descendente. Escultura da epiteca formada por um retículo irregular, com delicadas subdivisões. Na hipoteca o reticulado é mais regular, formando fileiras longitudinais facilmente visíveis e que apresentam cristas.

Tamanho: C: $65 \mu \mathrm{m}$; D: 27,5 $\mu \mathrm{m}$. O diâmetro foi menor do que reportado por Balech (1988).

Distribuição: A espécie foi somente observada na plataforma do CSMG durante o inverno, em temperatura de $17,8-21,4{ }^{\circ} \mathrm{C}$ e salinidade de 33,1-36,6. Segundo Balech (1988), apresenta preferência por águas mais quentes, mas ocorre também em águas frias neríticas e oceânicas. A espécie observada ocorreu em limites de temperatura e salinidade superiores aos registrados por Balech (1988), que a classificou como uma espécie muito tolerante a estas mudanças.

\section{Corythodinium tessellatum (Stein) Balech (Figura 44)}

Sinônimo: Oxytoxum tesselatum (Stein) Schütt; Corythodinium tesselatum (Stein) Loeblich Jr. e Loeblich III

As células são de tamanho médio, com a epiteca cônica, larga, relativamente baixa e coroada por uma pequena projeção. Cíngulo localizado na região anterior da célula, descendente com certo entrecruzamento. Hipoteca um pouco mais larga, maior que a epiteca, terminando em um espinho antiapical de tamanho médio. Escultura da epiteca marcada por estrias irregulares e ramificadas e um reticulado grande e irregular, pouco marcado. Hipoteca característica, com estrias longitudinais regularmente espaçadas, conectadas a estrias transversais bem definidas.

Tamanho: C: $50-55 \mu \mathrm{m}$; D: 30-35 $\mu \mathrm{m}$.

Distribuição: A espécie foi observada na plataforma continental nos dois períodos. Na região do CSMG durante o inverno (temperatura $17,8-21,4{ }^{\circ} \mathrm{C}$; salinidade $33,1-36,6$ ), e no AC durante o verão (temperatura $16,6-24,2{ }^{\circ} \mathrm{C}$; salinidade $33,5-36,6$ ). Esta espécie ocorre em águas temperadas tropicais, principalmente no Oceano Atlântico (Steidinger \& Tangen 1995). Segundo Balech (1988) dois grupos foram observados para a espécie, diferenciados pelo tamanho: os menores relacionados com águas 

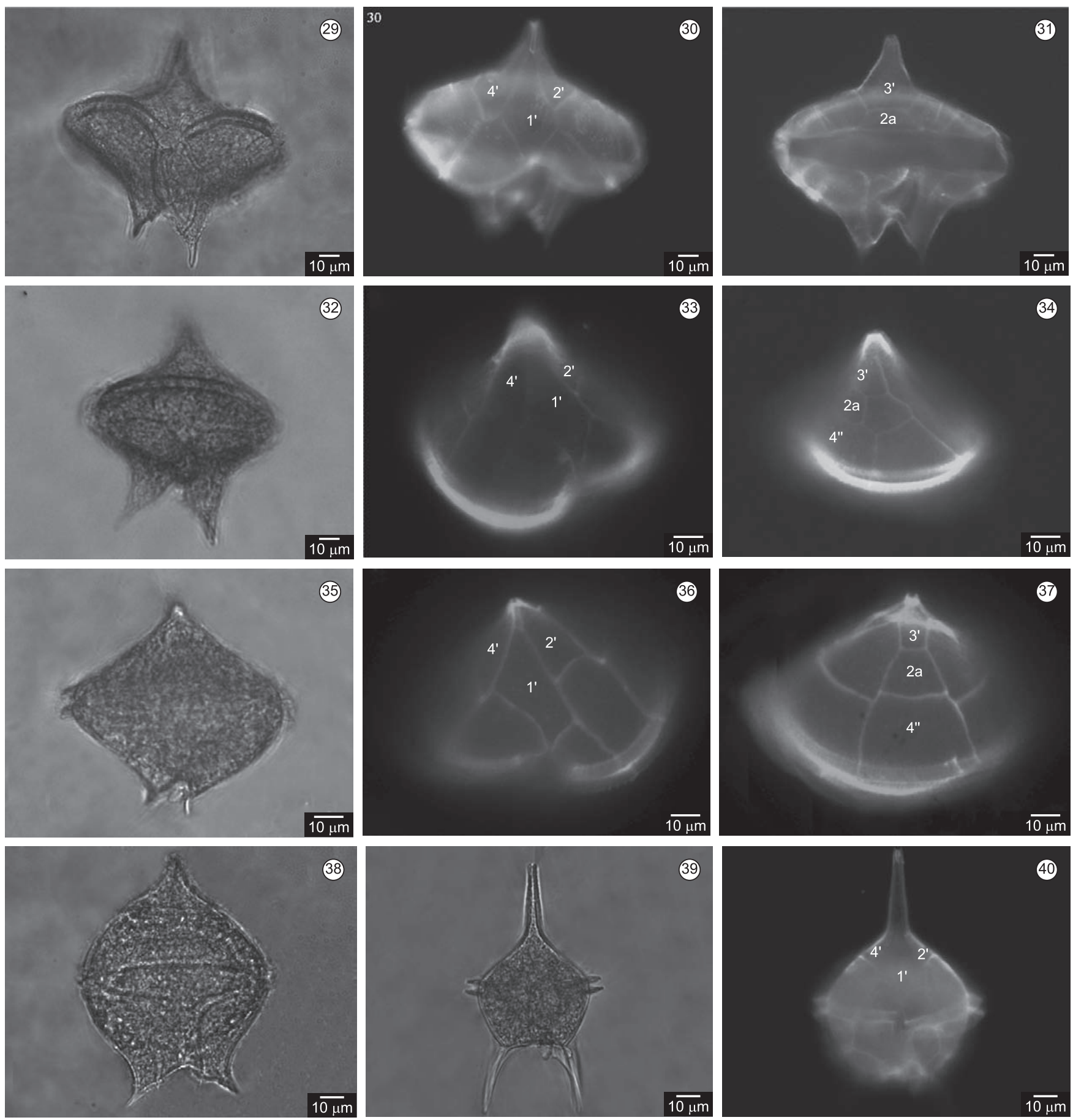

Figuras 29-40. 29-31 - Protoperidunium curtipes; 32-34 - P. divergens; 35-37 - P. cf. parviventer; 38 - Protoperidinium sp.; $39-40$ - P. longipes. Escala 10 $\mu$ m. Figures 29-40. 29-31 - Protoperidinium curtipes; 32-34 - P. divergens; 35-37 - P. cf. parviventer; 38 - Protoperidinium sp.; 39-40 - P. longipes. Scale $10 \mu \mathrm{m}$.

equatoriais e os maiores na região do Atlântico Sudoeste, sem nenhum significado taxonômico. Uma espécie freqüente em águas mais quentes, geralmente em temperatura superior a $16^{\circ} \mathrm{C}$, relacionada com a Corrente do Brasil.

\section{Oxytoxum milneri Murray \& Whitting (Figura 45)}

Sinônimo: Oxytoxum subulatum (Kofoid)

A epiteca cônica termina em um longo espinho apical, e a hipoteca tem a forma de um cone invertido (obcônica) de margens convexas, levemente constricta no terço posterior, terminada em um espinho. Presença de um núcleo grande na região mediana da hipoteca.

Tamanho: C: 75-107,5 $\mu \mathrm{m}$; D: 30-32,5 $\mu \mathrm{m}$.

Distribuição: A espécie foi observada na plataforma do AC durante o verão, em temperatura de $16,4-24,4{ }^{\circ} \mathrm{C}$ e salinidade de 33,5-36,6. Amplamente distribuída na região central do Brasil (RJ, ES, MG, BA), nas áreas nerítica e oceânica (Tenenbaum 2006), onde os organismos observados apresentaram os limites de comprimento e diâmetro maiores do que os registrados no presente estudo. O gênero Oxytoxum reúne espécies fototróficas 
de águas tropicais, subtropicais e temperadas quentes (Steindinger \& Tangen 1995).

\section{Oxytoxum scolopax (Stein) (Figura 46)}

As células são longas e estreitas, mais largas no centro e afilando nas extremidades. Epiteca curta, arredondada e pequena, prolongada em um grande espinho com membranas estreitas. Hipoteca longa, mais de quatro vezes o comprimento da epiteca e terminada em um espinho antiapical desenvolvido, geralmente precedido por um pequeno "bulbo", delimitado por um estrangulamento. Sulco pequeno e cíngulo profundo um pouco descendente. Em algumas células, foi observado um pequeno espinho abaixo do cíngulo, na região anterior da hipoteca.

Tamanho: CT: $110 \mu \mathrm{m}$; D: 12,5 $\mu \mathrm{m}$.

Distribuição: Observada durante o inverno na plataforma do CSMG, em temperatura de 17,8-21,4 ${ }^{\circ} \mathrm{C}$ e salinidade de 33,1-36,6. Segundo Balech (1988) a maioria dos exemplares foi observada em temperatura superior a $15{ }^{\circ} \mathrm{C}$ e salinidade superior a 34,5 . É uma espécie característica, ainda que algumas variações no comprimento e diâmetro sejam observadas. Termófila e oceânica, no entanto, tolerante a mudanças de temperatura e salinidade Balech (1988).

\section{Podolampas bipes Stein (Figura 47)}

As células têm forma piriforme com forte achatamento dorsoventral. Epiteca terminada em um processo curto e hipoteca terminada em um par de espinhos separados, sendo o direito mais largo.

Tamanho: LT: $61 \mu \mathrm{m}, \mathrm{L}: 47 \mu \mathrm{m}$; D: $35 \mu \mathrm{m}$. Comprimento e largura inferiores aos valores registrados por Balech, embora variações consideráveis na sua dimensão sejam observadas (Balech 1988).

Distribuição: Observada na plataforma do AC no cruzeiro de verão e do CSMG no de inverno, na faixa de temperatura de 16,6- $24,2^{\circ} \mathrm{C}$ e salinidade de 33,1-36,6. Ainda, os exemplares observados ocorreram em temperatura mais alta e em limite de salinidade mais baixa do que aqueles registrados por Balech (1988).

\section{Podolampas palmipes Stein (Figura 48)}

As células têm forma globular na vista ventral e dorsal, e piriforme em vista lateral. Possuem um par de espinhos antiapicais bem desenvolvidos e quase paralelos, sendo o esquerdo maior.

Tamanho: LT: 110-130 $\mu \mathrm{m}$, L: 77,5- 97,5 $\mu \mathrm{m}$; D: 20- 32,5 $\mu \mathrm{m}$. Os exemplares observados estiveram dentro do limite de tamanho reportado por Balech (1988), mas foram maiores que aqueles observados por Tenenbaum (2006).

Distribuição: Observada durante o inverno na plataforma do CSMG, em temperatura de $17,7-21,4{ }^{\circ} \mathrm{C}$ e salinidade de $33,1-36,6$. No Verão em AC, em temperatura de $16,6-24,2^{\circ} \mathrm{C}$ e salinidade de 33,5-36,6. $\mathrm{Na}$ tabela consta. Facilmente reconhecida, ainda que variações consideráveis de tamanho possam ocorrer (Balech 1988). A única espécie semelhante é $P$. antartica, que se diferencia por possuir um espinho apical, forma das membranas antiapicais e placa intercalar (Balech 1988). De ampla distribuição em águas quentes e frias (Balech 1988).

\section{Heterocapsa triquetra (Ehrenberg) F. Stein (Figura 49- 52)}

Sinônimo: Glenodinium triquetrum Ehrenberg, Peridinium triquetrum (Ehrenberg) Lebour; Properidinium heterocapsa (Stein) Meunier
As células são pequenas, delicadas, irregularmente fusiformes e facilmente reconhecíveis. Epiteca cônica reforçada no ápice e hipoteca, também cônica, terminada em um pequeno processo, facilmente confundidas, mas na altura média da epiteca, geralmente observam-se processos principalmente à direita da célula. $\mathrm{O}$ cíngulo situa-se na região mediana e é claramente descendente. O sulco é amplo, mas pouco nítido.

Tamanho: C: 25-40 $\mu \mathrm{m}$; D: 20-25 $\mu \mathrm{m}$. Comprimento e diâmetro um pouco maiores do que registrado por Balech (1988) e Hoppenrath et al. (2009).

Distribuição: Observada somente em uma estação costeira do AC (estação 33) durante o inverno, em temperatura de $13{ }^{\circ} \mathrm{C}$ e salinidade de 26,5-30,5, a menor salinidade registrada entre as estações de coleta para o período. Esta foi a espécie encontrada em maior número e a estimativa de sua concentração média na coluna de água, com base no arrasto vertical, foi de 3081 cels/L. É uma espécie nerítica, sobretudo costeira, de águas marinhas e salobras que suporta ampla variação de temperatura, observada em grande concentração na costa do Uruguai (Balech 1988). Parece ser cosmopolita, sendo comumente registrada nos mares do Norte e Báltico. Pode formar densas florações e causar a descoloração da água (Hoppenrath et al. 2009, Balech 1988). Os exemplares observados apresentaram seu comprimento e diâmetro um pouco maiores do que registrados por Balech (1988) e Hoppenrath et al. (2009).

\section{Discussão}

A plataforma continental entre o Cabo de Santa Marta Grande, CSMG e Albardao-Chuí, AC (Figura 1) é influenciada por diversas massas de água com propriedades termohalinas que variam em consequiência do volume de água doce descarregado pela pluma do Río de la Plata (PRP) e da Lagoa dos Patos e do grau de influência da Água Tropical e da Água Sub-antártica. Assim, podem ser encontradas na região de estudo, Água Subtropical de Plataforma (ASTP), Água Sub-antártica de Plataforma (ASAP), Água Tropical (AT), Água Costeira ou Pluma do Río de la Plata (PRP) e Água Central do Atlântico Sul (ACAS) (Möller et al. 2008). Durante o inverno de 2005, quatro massas de água (PRP, ASTP, AT e ACAS) foram observadas nas áreas nerítica e oceânica, situadas entre o CSMG e AC. Enquanto que no verão de 2007, além destas, a ASAP foi observada. Devido à mistura de águas de diferentes origens nesta região, verifica-se a importância de estudo sobre a biogeografia e espécies indicadoras, considerando-se o cenário de mudanças climáticas e possível alteração da temperatura nos oceanos

O tratado sobre os dinoflagelados na região do Atlântico Sudoeste realizado por Balech (1988) fornece além de minuciosos detalhes taxonômicos, dados de temperatura e salinidade, permitindo relacionar a distribuição das espécies com as massas de água presentes nesta região. Ainda, os trabalhos no extremo sul do Brasil (Haraguchi 2010), em Santa Catarina (Cardoso 1998), em Tramandaí (Kremer \& Rosa 1983) e na região sudeste e central do Brasil (Tenenbaum 2006) permitem aprofundar o conhecimento sobre os limites de distribuição dos dinoflagelados.

A maior riqueza de espécies de Protoperidinium do microplâncton foi observada no inverno na região costeira do $\mathrm{AC}$, sob a maior influência da pluma do Río de la Plata. Dez espécies de Protoperidinium, exclusivamente heterotróficas, foram mais expressivas nas amostras do inverno em Albardao-Chuí: P. curtipes, $P$. cassum var. cassum, $P$. depressum, $P$. divaricatum, $P$. divergens, $P$. longipes, $P$. oceanicum, P. obtusum, P. pentagonum e Protoperidinium. sp. A água doce, oriunda do Río de la Plata e da Lagoa dos Patos, se mistura com a água presente na plataforma continental formando uma camada flutuante de baixa salinidade, resultando em um forte gradiente 

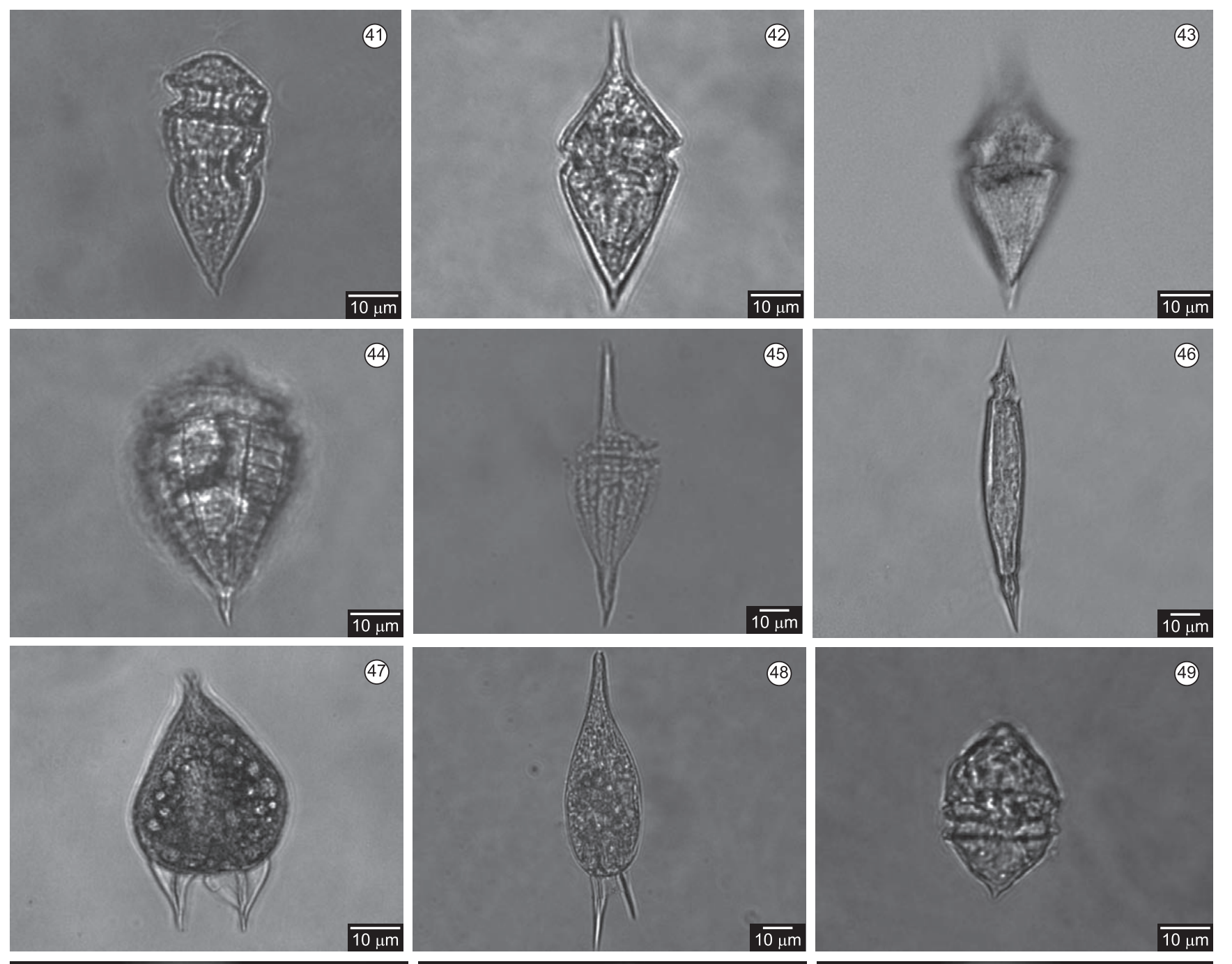

(48)
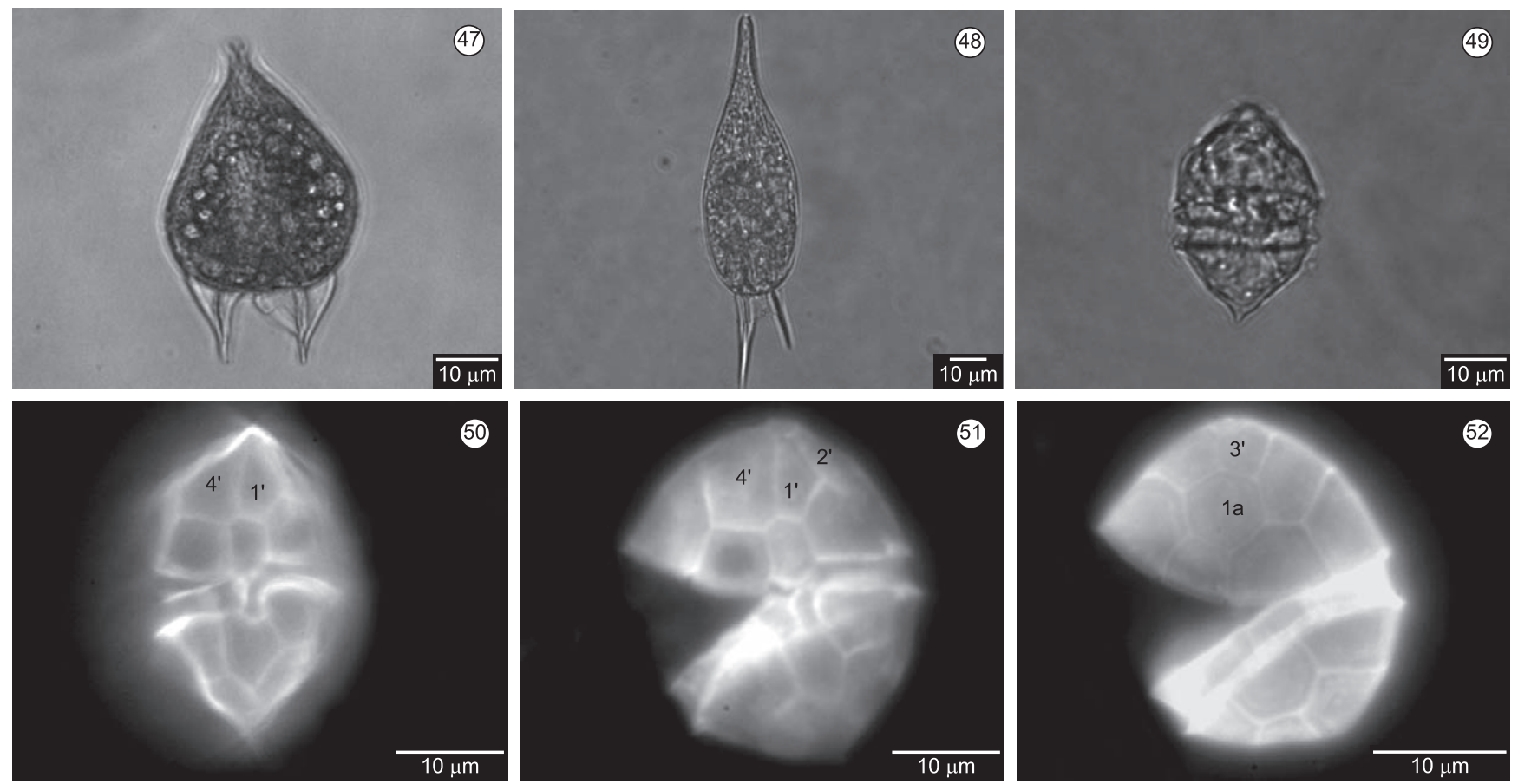

Figuras 41-52. 41 - Corythodinium constrictum; 42-43 - C. diploconus; 44 - C. tesselatum; 45 - Oxytoxum milneri; 46 - O. scolopax; 47 - Podolampas bipes; 48 - P. palmipes; 49-52 - Heterocapsa triquetra. Escala $10 \mu \mathrm{m}$.

Figures 41-52. 41 - Corythodinium constrictum; 42-43 - C. diploconus; 44 - C. tesselatum; 45 - Oxytoxum milneri; 46 - O. scolopax; 47 - Podolampas bipes; 48 - P. palmipes; 49-52 - Heterocapsa triquetra. Scala $10 \mu \mathrm{m}$.

vertical na densidade (Aseff 2009). A estrutura de densidade forma uma frente definida na borda da pluma (Möller et al. 2008) e esta estratificação favorece a permanência do fitoplâncton, especialmente dos dinoflagelados, na camada eufótica. A zona externa ao estuário do Río de la Plata na plataforma continental do Uruguai foi caracterizada pela presença de diatomáceas grandes e dinoflagelados Prorocentrales e Peridiniales do microplâncton, típicos de zonas costeiras (Ferrari 2008). Ainda, estes grupos foram observados co-dominando a comunidade fitoplanctônica ao longo da pluma do Río de la Plata durante o final da primavera (novembro, 2001) (Carreto et al. 2008). Não foi possível estabelecer uma relação entre a distribuição dos dinoflagelados e a massa de água em estações com a presença de diferentes tipos de água ao longo da coluna de água, tendo em vista a coleta de amostras por meio de arrastos verticais. Entretanto, alguns aspectos devem ser considerados. Protoperidinium obtusum foi observada principalmente sob influência da pluma do Río de la Plata em temperatura máxima de $16{ }^{\circ} \mathrm{C}$, da mesma forma como Balech (1988), que raramente a encontrou em temperatura superior 
a $17{ }^{\circ} \mathrm{C}$, podendo, portanto ser considerada como característica de águas mais frias. Foram associadas com ASTP, P. pentagonum e P. divergens com preferência por águas mais quentes (Balech 1988). Por outro lado, $P$. longipes que é considerada termófila (Balech 1988) foi observada na presença de águas tropicais, mas também em águas mais frias da ACAS. As espécies $P$. curtipes e $P$. oceanicum foram observadas em AC no inverno sob influência exclusiva da pluma do Río de la Plata, que possivelmente também influenciou a ocorrência de Prorocentrum minimum. Já Protoperidinium cf. parviventer, $P$. depressum, Corythodinium diploconus, $C$. constrictum e Podolampas palmipes não apresentaram uma relação evidente, pois estiveram presentes em águas sob influência da pluma do Río de la Plata, mas também de origem tropical (AT, ASTP) e ACAS. Porém, Corythodium spp., Oxytoxum spp. e Podolampas spp. foram observadas com maior frequência nas mesmas estações em CSMG no inverno e AC no verão. A presença de Podolampas bipes e Corythodinium tesselatum coincidiu com a influência de ASTP e ACAS.

Três espécies de Prorocentrum (P. gracile, P. micans e P. rostratum) foram mais frequentes nas amostras do verão, as primeiras com ampla distribuição em CSMG e AC e $P$. rostratum mais freqüente em AC, nas estações próximas ao talude e oceânicas, sob influência de águas tropicais e ACAS. Três espécies de Protoperidinium foram representativas no verão, $P$. divergens, $P$. parviventer e $P$. pentagonum parecem estar relacionadas principalmente com ASTP, com preferência por águas mais quentes (Balech 1988). A distribuição de Corythodinium tesselatum e Oxytoxum milneri, indicadoras de águas de origem tropical AT e ASTP (Balech 1988, Tenenbaum et al. 2006), foi relacionada a influência da Corrente do Brasil.

Uma grande concentração de H. triquetra (3081 cel/L) juntamente com Scrippsiella cf. trochoidea $(733 \mathrm{cel} / \mathrm{L})$, espécies relacionadas com densas florações e cistos de resistência (Hoppenrath et al. 2009), foi observada em uma estação do AC (est. 33) na presença exclusiva de águas da pluma do Río de la Plata, em amostra obtida em arrasto vertical com rede de plâncton (Islabão 2010). Em superfície foram observadas concentrações mais altas de Scrippsiella cf trochoidea (3550 cel/L) e outros Peridiniales (8260 cel/L) (Haraguchi com. Pessoal). Scrippsiella spp. e Heterocapsa spp. foram anteriormente observadas com elevada concentração nesta região (Persich \& Garcia 2003, Ciotti 1990). A morfologia e sedimentologia da plataforma continental da região do AC (Corrêa et al. 1996) é potencialmente propícia à ocorrência de cistos. Sugere-se que após o excistamento em condições ambientais favoráveis de temperatura, luz e calmaria, o crescimento das espécies é favorecido e resulta em grande concentração de células na coluna de água.

Espécies da Ordem Prorocentrales apresentaram ampla distribuição na plataforma continental do extremo sul do Brasil, onde o mesmo número de espécies foi observado em ambos os períodos. Como as espécies de Prorocentrum são autotróficas, pode-se supor que existe uma forte relação entre a sua densidade com a concentração de nutrientes na região. No AC, durante o inverno de 2005, foram observadas maiores concentrações de clorofila $a$, comparada a região do CSMG, relacionadas com a entrada de nutrientes com a pluma do Río de la Plata (Attisano 2007). Durante o verão, a concentração de espécies na região do CSMG esteve possivelmente relacionada com a ressurgência costeira da ACAS, também reconhecidamente rica em nutrientes (Braga 2008). Em geral, as águas costeiras formadas pela PRP dominam a plataforma continental do Sul do Brasil no inverno e podem, em condições de ventos favoráveis, alcançar a latitude de $28{ }^{\circ} \mathrm{S}$, próximo ao CSMG; no verão, a pluma fica normalmente restrita a $\sim 32{ }^{\circ} \mathrm{S}$. Os ventos e o volume de água descarregado são os principais fatores para este comportamento (Möller et al. 2008).
As espécies Heterocapsa triquetra, Protoperidinium cassum var. cassum e Protoperidinium curtipes têm seu primeiro registro no Brasil e Oxytoxum milneri na região sul. As espécies $P$. cassum var. cassum e $P$. curtipes estiveram relacionadas com águas mais frias, a primeira observada na faixa de $13-21{ }^{\circ} \mathrm{C}$ e a segunda em $13{ }^{\circ} \mathrm{C}$. Oxytoxum milneri, amplamente distribuída na região central do Brasil, foi relacionada com a presença de águas mais quentes da corrente do Brasil, e H. triquetra, espécie nerítica, sobretudo costeira, suporta uma ampla variação de temperatura e salinidade e estava relacionada com águas da pluma do Río de la Plata. Esta espécie é também observada em alta concentração na costa do Uruguai (Balech 1988, Ferrari \& Vidal 2006).

O presente trabalho teve por objetivo aprofundar o conhecimento sobre a biodiversidade dos dinoflagelados do microplâncton na região do extremo sul do Brasil e sua relação com as condições oceanográficas, com ênfase na identificação das espécies de Prorocentrales e Peridiniales. A maior riqueza de espécies na área costeira do AC durante o inverno esteve relacionada com a influência da pluma do Río de la Plata, destacando-se Protoperidinium oceanicum, P. depressum, P. curtipes, Prorocentrum minimum e Heterocapsa triquetra. Protoperidinium divaricatum, $P$. longipes, Corythodinium tesselatum e Oxytoxum milneri estiveram relacionados com Águas Tropicais, e Protoperidinium pentagonum, $P$. divergens e $P$. cf. parviventer com a água Subtropical de Plataforma. A distribuição de Prorocentrum rostratum e Podolampas bipes também esteve relacionada com essas águas mais quentes e ainda com a Água Central do Atlântico Sul.

\section{Agradecimentos}

Este estudo foi realizado com o apoio do CNPq através de uma bolsa de mestrado para Carolina Antuarte Islabão e financiamento do Projeto PRONEX - FURG.

\section{Referências Bibliográficas}

ASEFF, C.R.C. 2009. Estudo da variação sazonal na composição físicoquímica das massas de água da plataforma continental do Atlântico Sodoeste (PCASO) entre Mar del Plata (Argentina, $38^{\circ} \mathrm{S}$ ) e Itajaí (SC, $\left.26^{\circ} \mathrm{S}\right)$. Dissertação de Mestrado, Universidade Federal do Rio Grande, Rio Grande, 100 p.

ATTISANO, K.K. 2007. A oceanografia química e os processos oceanográficos presentes na Plataforma Continental das regiões de Santa Marta (SC) e Albardão (RS). Dissertação de Mestrado, Universidade Federal do Rio Grande, Rio Grande, 141 p.

BALECH, E. 1988. Los dinoflagelados del Atlântico Sudoccidental. Instituto Español de Oceanografia, Madrid. 310 p.

BÉRARD-THERRIAULT, L., POULIN, M. \& BOSSÉ, L. 1999. Guide d'identification du phytoplankton marin de I'estuaire et du golfe du Saint-Laurent incluant également certains protozoaires. Publ. Spec. Can. Sci. Halieut. Aquat. 128:1-387.

BRAGA, E.S., CHIOZZINI V.C., BERBEL G.B.B., MALUF J.C.C., AGUIAR V.M.C., CHARO M., MOLINA D., ROMERO S.I \& EICHLER B.B. 2008. Nutrient distributions over the Southwestern South Atlantic continental shelf from Mar del Plata (Argentina) to Itajaí (Brazil): Winter-summer aspects. Cont. Shelf Res. 28: 1649-1661. http://dx.doi. org/10.1016/j.csr.2007.06.018

CALLIARI, L.J. 1998. O ambiente e a biota do estuário da Lagoa dos Patos. In Os Ecossistemas Costeiro e Marinho do Extremo Sul do Brasil (U. Seeliger, C. Odebrecht \& J.P. Castello, eds.). Ecoscientia, Rio Grande, 341 p.

CARDOSO, S.L. 1998. Dinoflagelados da Ilha do Arvoredo e da Praia de Ponta das Canas, Santa Catarina, Brasil. Biociências 6(1):3-54. 
CARRETO, J.I., MONTOYA, N., AKSELMAN, R., CARIGNAN, M.O., SILVA, R.I. \& COLLEONI, D.A.C. 2008. Algal pigment patterns and phytoplankton assemblages in different water masses of the Río de la Plata maritime front. Cont. Shelf Res. 28:1589-1606. http://dx.doi. org/10.1016/j.csr.2007.02.012

CIOTTI, A.M. 1990. Fitoplâncton da plataforma continental do Sul do Brasil: clorofila a, feopigmentos e análise preliminar da produção primária (outubro de 1987 e setembro de 1988). Dissertação de mestrado, Universidade do Rio Grande, Rio Grande, 86 p.

COHEN-FERNANDEZ, E.J., CASTILLO, E.M.D., HUGARTE, I.H.S. \& PEDRPCHE, F.F. 2006. Contribution of external morphology in solving a species complex: The case of Prorocentrum micans, Prorocentrum gracile and Prorocentrum sigmoides (Dinoflagellata) from the Mexican Pacific Coast. Phycol. Res. 54:330-340.

CORRÊA, I.C.S., VILLWOCK, J.A., ISLA, F.I., LABORDE, J.L., JACKSON, J.M., FURTADO, V.V. \& CALLIARI, L.J. 1996. Atlas morphology and sedimentology of the southwest Atlantic coastal zone and Continental Shelf from Cabo Frio (Brazil) to Península Valdés (Argentina). Ponto Um, UFRGS-IG-CECO, Porto Alegre. 20 mapas.

DODGE, J.D. 1975. The Prorocentrales (Dinophyceae). II. Revision of the taxonomy within the genus Prorocentrum. Bot. J. Linn. Soc. 71:103-125. http://dx.doi.org/10.1111/j.1095-8339.1975.tb02449.x

FAUST, M.A \& GULLEDGE, R.A. 2002. Identifying harmful marine dinoflagellates. Washington: Smithsonian Instituition, United States National Herbarium, v. 42, p.1-144.

FAUST, M.A., LARSEN, J. \& MOESTRUP, Ø. 1999. Potentially toxic phytoplankton. 3. Genus Prorocentrum (Dinophyceae), ICES Identification Leaflets for Plankton, Leaflet n. 184:1-23.

FERRARI, G.C. 2008. Fitoplancton del Estuario del Rio de La Plata y Frente Oceanico: Su relacion com las massas de água. Dissertação de Mestrado, Universidade de la República, Uruguay, 113 p.

FERRARI, G.C. \& VIDAL, L. 2006. Fitoplancton de la zona costera uruguaya. Río de la Plata y Oceano Atlántico. In Bases para la conservación y el manejo de la costa uruguaya (R. Menafra, L. Rodríguez-Gallego, F. Scarabino \& D. Conde, eds.). Vida Silvestre, Uruguay, 667 p.

FRITZ, L. \& TRIEMER, R.E. 1985. A rapid simple technique utilizing calcofluor white M2R for the visualization of dinoflagellate thecal plates. J. Phycol. 21:662-664. http://dx.doi.org/10.1111/j.00223646.1985.00662.x

FUKUYO, Y., TAKANO, H., CHIHARA, M. \& MATSUOKA, K. 1990. Red tide organisms in Japan. An illustrated taxonomic guide. Uchida Rokakuho, Co., Ltd., Tokyo, Japan, 407p.

GOMEZ, F. 2005. A list of free-living dinoflagellate species in the world's oceans. Acta Bot. Croat. 64(1):129-212.

HALLEGRAEFF, G.M., ANDERSON, D.M. \& CEMBELLA, AD. 2004. Manual on Harmful Marine Microalgae. UNESCO, France, 793 p.

HARAGUCHI, L. 2010. Distribuição espacial da ordem Dinophysiales (dinoflagelados) no extremo sul do Brasil no inverno de 2005 e verão 2007. Monografia, Universidade Federal do Rio Grande, Rio Grande, 42 p.

HARAGUCHI, L. \& ODEBRECHT, C. 2010. Dinophysiales (Dinophyceae) no extremo Sul do Brasil (inverno de 2005, verão de 2007). Biota Neot. 10(3).

HOPPENRATH, M., ELBRACHTER, M. \& DREBES, G. 2009. Marine Phytoplankton: Selected microphytoplankton species from the North Sea around Helgoland and Sylt. Germany: E. Schweizerbart'sche Verlagsbuchhandlung (Nagele u. Obermiller), Stuttgart. 264 p.

ISLABÃO, C.A. 2008. Estudo do gênero Prorocentrum Ehrenberg (Dinoflagellata) na Plataforma Continental do Rio Grande do Sul (verão, 2007). Universidade Federal do Rio Grande, Monografia de Especialização. $41 \mathrm{p}$

KREMER, L.M \& ROSA Z.M. 1983. Dinoflagelados do microplâncton de Tramandaí, Rio Grande do Sul, Brasil. Iheringia Ser Bot (Porto Alegre) 30: $3-35$.
LU, D., GOEBEL, J., QI, Y., ZOU, J., HAN, X., GAO, Y. \& LI, Y. 2005. Morphological and genetic study of Prorocentrum donghaiense Lu from the East China Sea, and comparison with some related Prorocentrum species. Harmful Algae 4:493-505. http://dx.doi.org/10.1016/j. hal.2004.08.015

MÖLLER, O.O., PIOLA, A.R., FREITAS, A.C. \& CAMPOS, E.J.D. 2008. The effects of river discharge and seasonal winds on the shelf off southeastern South America. Cont. Shelf Res. 1607-1624. http://dx.doi. org/10.1016/j.csr.2008.03.012

PAVILLARD, J. 1916. Recherches sur les péridiniens du Golf du Lion. Trav. Inst. Bot. Univ. Montpellier, Sér. mexte, mem. 4:9-70.

PEDROSO, V.M. 2010. O gênero Neoceratium F. Gómez, D. Moreira et P. Lópes-Garcia (Dinophyta) na Plataforma Continental do Rio Grande do Sul, Brasil. Universidade Federal do Rio Grande, Monografia de Especialização, 38 p.

PERSICH, G.R. 1993. Ciclo Anual do Fitoplâncton e alguns parâmetros abióticos no Saco da Mangueira, estuário da Lagoa dos Patos. Dissertação de Mestrado, Universidade Federal do Rio Grande, Rio Grande, 92 p.

PERSICH, G.R \& GARCIA, V.M.T. 2003. Ocorrência de cistos de dinoflagelados, com ênfase em espécies potencialmente nocivas, no sedimento próximo à desembocadura da Laguna dos Patos (RS). Atlântica, Rio Grande, v. 25, n. 2, p.123-133.

REVIERS, B. 2006. Biologia e Filogenia das Algas. Artmed, Porto Alegre, $280 \mathrm{p}$.

SAR, E.A., FERRARIO, M.E. \& REGUERA, B. 2002. Floraciones algales nocivas en el Cono Sur Americano. Instituto Español de Oceanografia, España, $311 \mathrm{p}$.

ROSA, Z.M. \& BUSELATO, T.C. 1981. Sobre a ocorrência de floração de Gyrodinium aureolum Hulburt (Dinophyceae) no litoral sul do Estado do Rio Grande do Sul, Brasil. Iheringia Ser. Bot. 28:169-179.

SCHILLER, J. 1933. Dinoflagellatae (Peridineae) in monographischer Behandlung. In (L. Rabenhorst, ed.) Kryptogamen Flora von Deutschland, Österreich und Schweiz. Akademische Verlags., Leipzig. 10(1):617.

SCOTT, F.J. \& MARCHANT, H.J. 2005. Antarctic Marine Protists. Australian Biological Resources Study, Canberra, Austrália, 563 p.

SEELIGER, U., ODEBRECHT, C. \& CASTELLO, J.P., eds. 1998. Os Ecossistemas Costeiro e Marinho do Extremo Sul do Brasil. Ecoscientia, Rio Grande, $341 \mathrm{p}$.

SOURNIA, A., BELIN C., BERLAND B., ERARD-LE DENN E., GENTIEN P, GRZEBYK D., MARCAILLOU-TE BAUT C, LASSUS P \& PARTENSKY F. 1991. Le phytoplankton muisible des côtes de France. Istitut francais de recherché pour L'exploitation de la mer, Brest. 154p.

STEIDINGER, K.A. \& TANGEN, K. 1995. Dinoflagellates. In Identifying marine Diatoms and Dinoflagellates (Tomas C., ed.). Academic Press, California, p.387-584

TAYLOR, F.J.R. 1987. The biology of dinoflagellates. Botanical Monographs, v. $21,785 \mathrm{p}$

TENENBAUM, D.R. org. 2006. Dinoflagelados e Tintinídeos da região central Zona Econômica Exclusiva Brasileira: guia de identificação. Museu Nacional, Rio de Janeiro.

UCHIDA, T. 1997. Excretion of a diatom-inhibitory substance by Prorocentrum micans Ehrenberg. Jap. J. Ecol. 27:1-4.

YAMAGUCHI, A., KAWAMURA, H. \& HORIGUCHI, T. 2006. A further phylogenetic study of the heterotrophic dinoflagellate genus, Protoperidinium (Dinophyceae) based on small and large subunit ribossomal RNA gene sequences. Phycol. Res. 54:317-329. http://dx.doi. org/10.1111/j.1440-1835.2006.00438.x

YAMAJI, I. 1984. Illustrations of the Marine Plankton of Japan. Hoikusha Publishing, Japão, 537 p. 